\title{
Refined Avian Risk Assessment for Chlorpyrifos in the United States
}

\author{
Dwayne R.J. Moore, R. Scott Teed, Colleen D. Greer, \\ Keith R. Solomon, and John P. Giesy
}

\section{Introduction}

Chlorpyrifos (O,O-diethyl O-(3,5,6-trichloro-2-pyridinyl) phosphorothioate; $\mathrm{CPY})$ is a widely used, organophosphorus insecticide that was first registered in the United States in 1965. It is available in flowable and granular formulations under the trademark Lorsban ${ }^{\circledR}$ and is registered in many countries for control of pests in soil or on foliage. Birds are potentially at risk following application of CPY because: (1) they forage in areas that could be treated with the pesticide, and (2) CPY has been shown to be toxic to birds under laboratory conditions when they were exposed to ecologically relevant concentrations in the diet. Here we present a refined assessment of risk to birds from application of granular or flowable formulations of CPY to crops in the United States at rates and frequencies of use approved on the current product labels. This assessment focused on bird species that are known to frequently forage in crop fields treated with CPY.

The online version of this chapter (doi:10.1007/978-3-319-03865-0_6) contains supplementary material, which is available to authorized users.

D.R.J. Moore $(\bowtie) \bullet$ C.D. Greer

Intrinsik Environmental Sciences (US), Inc., New Gloucester, ME, USA

e-mail: dmoore@intrinsikscience.com

R.S. Teed

Intrinsik Environmental Sciences, Inc., Carleton University Technology

and Training Center - Suite 3600, Ottawa, ON, Canada

K.R. Solomon

Centre for Toxicology, School of Environmental Sciences, University of Guelph,

Guelph, ON, Canada

J.P. Giesy

Department of Veterinary Biomedical Sciences and Toxicology Centre,

University of Saskatchewan, 44 Campus Dr., Saskatoon, SK S7N 5B3, Canada 
Mammals are far less sensitive than birds to acute exposures of chlorpyrifos (see review in Solomon et al. 2001). In addition, mammals are less exposed to granular CPY because they do not consume grit to aid digestion as do birds (Solomon et al. 2001). Therefore, risks due to exposure to CPY are likely to be greater for birds than for mammals. We did not conduct a refined risk assessment for mammals because any mitigations stemming from the avian risk assessment should also be protective of mammals foraging in treated fields.

This assessment builds upon past assessments of CPY, including the most recent EPA re-registration assessment (USEPA 1999) and a refined risk assessment to birds by Solomon et al. (2001). Using a conservative, screening-level risk assessment approach, the USEPA (1999) concluded that single and multiple applications of CPY potentially pose risks to birds. However, a more refined assessment of exposure based on simulations and analyses of field studies and incident reports demonstrated that the risks of exposure to flowable and granular CPY were small (Solomon et al. 2001). Solomon et al. (2001) used a probabilistic individual-based model to predict mortality for eight focal species exposed to flowable and granular CPY in corn. The model predicted that the eight focal species would not experience any mortality. Since the completion of the assessments by USEPA (1999) and Solomon et al. (2001), the labels have been amended to require buffer zones, reduce single and seasonal application rates, reduce the number of applications per season, and increase the minimum re-treatment intervals (USEPA 2009). In addition, EPA is preparing a new assessment of risk of flowable and granular formulations of CPY to birds that will make use of their standard screening-level risk assessment approach (USEPA 2008a). An initial draft of the reassessment by EPA was to be released for public comment in the latter part of 2013 (USEPA 2009).

A refined assessment of risks posed by labeled uses of CPY in agriculture in the USA was conducted to reflect changes made to the label and the availability of new information and methods for conducting exposure assessments of birds to insecticides. We initiated the preparation of this assessment by carefully formulating the problem to be addressed. Such problem formulation establishes the scope of the assessment, including defining the routes of exposure to be considered, focal species of birds and patterns of use. The problem formulation concludes with an analysis plan. Subsequent sections describe the methods and assumptions for assessing exposure and effects and characterization of risks. This paper is part of a series that describes the properties and environmental chemodynamics (Solomon et al. 2014), long-range atmospheric transport (Mackay et al. 2014), concentrations in aquatic environments (Williams et al. 2014), risks to aquatic organisms (Giddings et al. 2013), and risks to pollinators (Cutler et al. 2014) of CPY.

\section{Problem Formulation}

The goal of problem formulation is to develop a plan for the analysis that will guide the assessment of risks to terrestrial birds. To accomplish this task, the following topics are briefly reviewed: (1) patterns and amounts of CPY used; (2) formulations; 
(3) transformation products in the environment; (4) routes of exposure; and (5) mode of toxic action and thresholds for effects. The information cogent to these topics was used to create a conceptual model and identify focal avian species for the assessment. The problem formulation concludes with a list of exposure scenarios that were included in the refined avian risk assessment and an overview of the analysis plan.

\subsection{Patterns of Use}

Chlorpyrifos is an organophosphate insecticide that provides broad spectrum control of insects in cereal, oil, forage, nut, and vegetable crops (Solomon et al. 2014; USEPA 2011). The focus of this assessment is on representative current use flowable and granular formulations of Lorsban, i.e., Lorsban ${ }^{\circledR}$ Advanced and Lorsban ${ }^{\circledR} 15 \mathrm{G}$, respectively.

Chlorpyrifos is registered for use on a wide variety of crops including Brassica vegetables, corn, onion, peanut, sugar beet, sunflower, and tobacco for the granular formulation (Lorsban 15G), as well as alfalfa, Brassica vegetables, citrus, corn, cotton, grape, mint, onion, peanut, pome and stone fruits, soybean, sugar beet, sunflower, sweet potato, tree nuts, and wheat for the flowable formulations (e.g., Lorsban Advanced) (Gomez 2009; Solomon et al. 2014). The greatest amounts of CPY used in 2007 were applied to soybean, corn, almond, apple, alfalfa, wheat, and pecan (Gomez 2009; Solomon et al. 2014). Chlorpyrifos is widely used in the Midwest and Plains regions, California, Florida and Georgia because these are the primary growing areas for many row crops, citrus and tree nuts. For additional information on CPY use patterns, see Sect. 2.8 and Solomon et al. (2014).

\subsection{Formulations}

The focus of this risk assessment is on two formulations, the granular and the flowable. Lorsban 15G (Dow AgroSciences 2008) is a clay-based (e.g., montmorillonite, bentonite) granular formulation containing $15 \%$ active ingredient. Lorsban Advanced (Dow AgroSciences 2009) is a flowable formulation, specifically an emulsion in water that contains $40.2 \%$ active ingredient.

\subsection{Metabolites of CPY in the Environment}

The fate and transport of CPY in the environment is reviewed in Mackay et al. (2014). In this section, we focus on degradates of CPY in the environment that could be relevant to the avian risk assessment. The major transformation product of hydrolysis of CPY in alkaline soil is 3,5,6-trichloro-2-pyridinol (TCP) (Solomon et al. 2014). TCP is non-toxic to birds at concentrations greater than what would be encountered in the environment (acute $\mathrm{LD}_{50}>1,000 \mathrm{mg}$ ai kg-1 bwt, chronic $\mathrm{LC}_{50} \mathrm{~S}$ 
of 500-5,600 mg ai kg-1 in the diet) (Campbell et al. 1990; Long et al. 1990; Miyazaki and Hodgson 1972). Transformation products of TCP are also not toxic to birds at concentrations observed in the environment (Racke 1993). The oxon of CPY (CYPO; $O$-ethyl $O$-(3,5,6-trichloro-2-pyridinol) phosphorothionate) is formed in vivo in birds by oxidative desulfuration (Testai et al. 2010). This metabolite is shorter lived in the environment than CPY and is rapidly degraded via hydrolysis to TCP and diethylphosphate (Mackay et al. 2014). The oxon of CPY is toxic to non-target organisms, including birds, but poses little risk because it is formed in very small quantities in the terrestrial environment and is rapidly degraded (Bidlack 1979; Chapman and Harris 1980; de Vette and Schoonmade 2001). The Pesticide Management Regulatory Agency of Canada (PMRA) (2007) did not consider CPYO to pose a risk to birds. Another transformation product, 3,5,6-trichloro-2methoxypyridine (TMP) has also been reported in aerobic biodegradation studies (Bidlack 1979; Racke 1993). The half-life of TMP is similar to that of TCP and is not toxic to birds at concentrations observed in the environment (Racke 1993; Reeves 2008). For the reasons cited above, TCP, CPYO, and TMP were not considered in this refined assessment of risks of CPY to birds.

\subsection{Routes of Exposure for Birds in Terrestrial Environments}

Based on the physical and chemical properties of CPY (Solomon et al. 2014), bioaccumulation of CPY could occur. It is not likely, however, to be a significant pathway of exposure for birds because CPY is rapidly metabolized with a half-life of approximately 1-d (Barron and Woodburn 1995; Mackay et al. 2014; Racke 1993; Smith et al. 1967). Because CPY has a half-life of 2-5-d on foliage under field conditions (Williams et al. 2014), acute exposure is the primary concern. Although not persistent in the field, there is the potential for chronic exposure because flowable CPY may be applied up to four times per season with intervals as short as 10-d. Therefore, for flowable CPY, both acute and chronic risks to birds were estimated. Because granular CPY can only be applied once per season (Solomon et al. 2014), only acute risks were estimated for this formulation.

Whether applied as a granular or flowable formulation, wind and rain cause penetration of CPY into soil (Solomon et al. 2001), and volatilization from moist soil surfaces is rapid (HSDB 2013; Mackay et al. 2014). Once below the soil surface, CPY is much less available to birds. The most likely routes of exposure of birds to CPY following application of the flowable formulation are through the ingestion of residues on plants and prey and in drinking water. Exposure to CPY through inhalation, dermal contact, and preening are also routes of exposure for birds following application of flowable CPY. However, the results of several studies conducted with turkeys (Meleagris gallopavo) (Kunz and Radeleff 1972; McGregor and Swart $1968,1969)$ indicate that uptake from dermal exposure directly from soil and vegetation sprayed at maximum allowable rates on the Lorsban Advanced label, and any subsequent preening would not cause adverse effects (Solomon et al. 2001). By performing an analysis with the USEPA (2010) Screening Tool for Inhalation 
Risk (STIR), version 1.0, we determined that inhalation of CPY would not be a significant exposure pathway for birds. In that analysis, airblast application at the largest permitted, single application rate on the Lorsban Advanced label (i.e., $6.23 \mathrm{~kg} \mathrm{ha}^{-1}$ (5.6 $\mathrm{lb}$ ai $\mathrm{A}^{-1}$ for oranges)), and a vapor pressure of $0.0000202 \mathrm{~mm} \mathrm{Hg}$ (0.00269 Pa) (Solomon et al. 2014; USEPA 2009) were assumed. When the predicted exposure was compared to the lowest oral $\mathrm{LD}_{50}$ for birds, i.e., $5.62 \mathrm{mg}$ ai kg-1 bwt for common grackle (Schafer and Brunton 1979), the results of STIR predicted that exposure via inhalation "is not likely significant" for birds exposed to CPY on treated fields immediately after application at the maximum permitted rate on the label for Lorsban Advanced. Thus, the most important routes of exposure for birds following application of flowable CPY are ingestion of residues on food items and ingestion of water from on-field puddles and other drinking water sources (e.g., dew). These routes of exposure were the focus of the avian risk assessment for flowable CPY.

Following application of the flowable formulation, CPY can reach offsite soil, water bodies, terrestrial vegetation, and insects from spray drift, runoff and erosion (Williams et al. 2014). Some CPY will dissipate into the air, either becoming airborne during application or volatilizing from treated surfaces (Mackay et al. 2014). Chlorpyrifos in air may be transported by wind and deposited offsite, but amounts will be small (Mackay et al. 2014). Direct application of CPY to streams, lakes, and ponds is not permitted by product labels. Because exposure will be greatest on treated fields, assessment of risks of flowable CPY to birds was estimated for birds foraging on-field. Risks to birds foraging off-field would be much less.

Following application of granular CPY, unincorporated and intact granules might be directly ingested by birds while they are foraging for grit (Luttik and de Snoo 2004; Moore et al. 2010b, c). When water has collected on the soil surface where granules have been applied, birds might ingest dissolved CPY from pooled water. However, farmers do not normally apply granular pesticides when soil is saturated with water or when significant precipitation is expected within a day or two of application. Exposure via dermal contact is expected to be minimal because the CPY that exists in granules is unlikely to be available for transport across feathers and the bird epidermis. This assumption is supported by the results of a study involving penned turkeys (M. gallopavo) that were exposed to 5\% CPY in granules applied to soil at a rate of $3.36 \mathrm{~kg} \mathrm{ha}^{-1}$ (3 $\mathrm{lb}_{\mathrm{bi} \mathrm{A}}{ }^{-1}$ ) (Price et al. 1972). The only labeled crop having a higher maximum application rate for granular CPY (Lorsban $15 \mathrm{G}$ ) is peanuts (i.e., $4.48 \mathrm{~kg} \mathrm{ha}^{-1}$ ). No toxicity occurred during the 4-wk study, indicating that turkeys did not accumulate significant amounts of CPY through their feet or feathers. Thus, the focus of the assessment of for the granular formulation was on birds exposed to CPY granules while foraging for grit to aid digestion.

\subsection{Toxicity and Mode of Action}

As with other organophosphorus pesticides, CPY is rapidly absorbed following ingestion in food and water. It then undergoes oxidative metabolism to form CPYO, 
which is the chemical primarily responsible for toxicity (Solomon et al. 2014). The oxon of CPY binds to the enzyme that hydrolyzes the neurotransmitter acetylcholine, i.e., acetylcholinesterase (AChE). The resulting accumulation of acetylcholine causes overstimulation of cholinergic synapses (Testai et al. 2010). Exposure to CPY in birds can be detected biochemically as reduced activity of AChE in blood plasma or brain (Parsons et al. 2000; Testai et al. 2010). Other symptoms of toxicity include loss of mass, ruffled appearance, loss of coordination, reduced reaction to sound and movement, wing droop, prostrate posture, weakness of lower limbs, lethargy, gaping, salivation, muscle fasciculation, convulsions, and death (Gallagher et al. 1996).

Acute dietary studies have been conducted to determine toxicity in birds. However, birds tend to avoid treated food with high CPY concentrations (see SI Appendix 3, Sect. 1.2), which limits the usefulness of studies in which CPY is fed in the diet to derive dose-response relationships. Five-d GLP (Good Laboratory Practice) dietary studies yielded $\mathrm{LC}_{50}$ values of $2,772 \mathrm{mg}$ ai $\mathrm{kg}^{-1}$ diet for northern bobwhite (Colinus virginianus) (Beavers et al. 2007), and $1,083 \mathrm{mg}^{\mathrm{ai} \mathrm{kg}} \mathrm{kg}^{-1}$ diet for mallards (Anas platyrhynchos) (Long et al. 1991). Based on the results of acute, oral gavage studies, $\mathrm{LD}_{50} \mathrm{~s}$ ranged from $5.62 \mathrm{mg}$ ai kg-1 bwt for adult common grackles (Q. quiscula) (Schafer and Brunton 1979) to $112 \mathrm{mg}^{2} \mathrm{~kg}^{-1}$ bwt for mallard ducklings (A. platyrhynchos) (Hudson et al. 1984). In an 8-wk study, in which adult mallards were fed CPY, a NOEC (no-observed effects concentration) of $100 \mathrm{mg} \mathrm{ai} \mathrm{kg}^{-1}$ diet was observed (Fink 1977). Reduced consumption of food and production of fewer eggs, and overt signs of toxicity, such as ataxia, ruffled appearance, weakness of lower limbs, and lethargy, were observed at the lowest observed effect concentration (LOEC) of $215 \mathrm{mg}$ ai $\mathrm{kg}^{-1}$ diet or greater concentrations. A reproductive study in mallard of CPY effects, in which adults were exposed to treated diet for 9-wk prior to egg laying and for 8-wk during egg laying, reported a NOEC of $25 \mathrm{mg}$ ai $\mathrm{kg}^{-1}$ diet and a LOEC of $125 \mathrm{mg}$ ai $\mathrm{kg}^{-1}$ diet (Fink 1978a). A similar study of CPY effects on reproduction of the northern bobwhite reported a NOEC at the greatest concentration tested, $125 \mathrm{mg}$ ai kg-1 diet (Fink 1978b).

\subsection{Conceptual Model}

A conceptual model provides a written and visual description of possible exposure routes between ecological receptors and a stressor. The model includes hypotheses for how a stressor might come into contact with and affect receptors. These hypotheses are derived by use of professional judgment and information available on sources of exposure, characteristics of the stressor (e.g., chemistry, fate, and transport), ecosystems at risk, and anticipated effects to birds. The conceptual model for evaluating potential risks to birds from the application of CPY as a flowable (Fig. 1) product illustrates that the most likely routes of exposure of birds are ingestion of foliage, seeds, fruits, insects, and drinking water from pools or foliage in the treated area. For granular CPY (Fig. 2), exposure is most likely to be the result of direct consumption of granules mistaken for grit. 


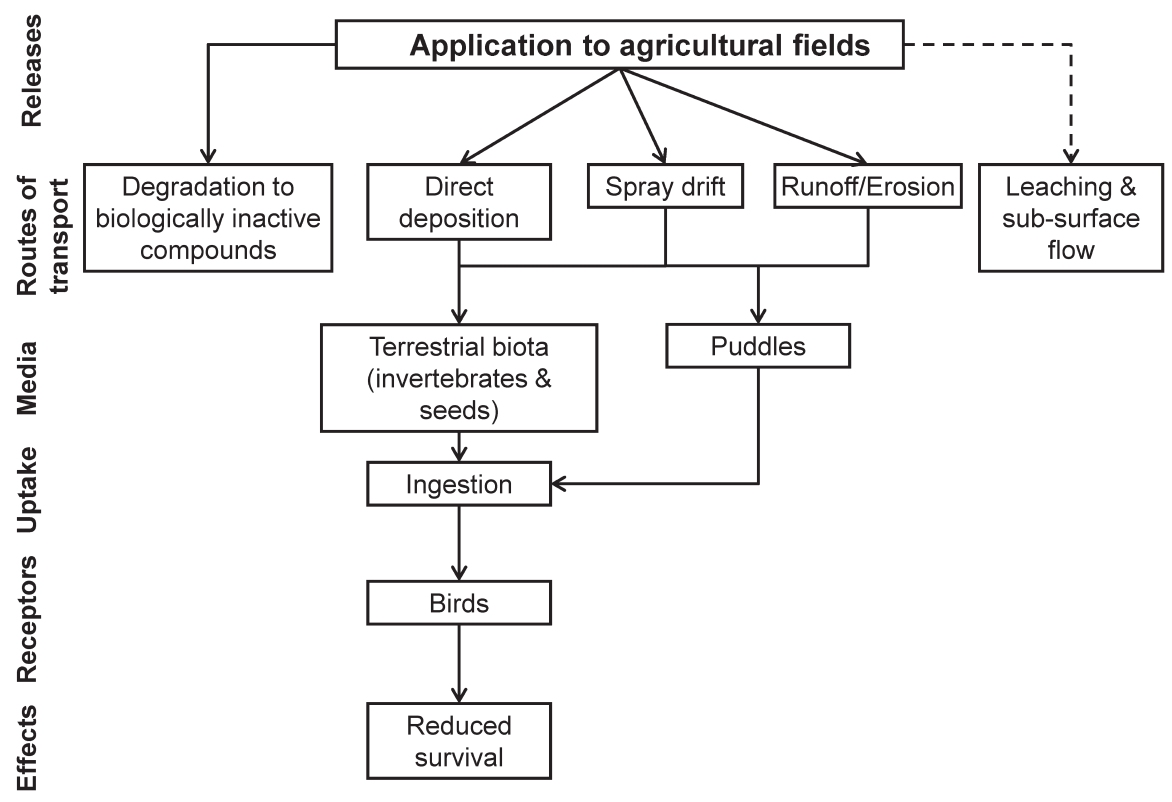

Fig. 1 Conceptual model for exposure of birds to flowable chlorpyrifos



Fig. 2 Conceptual model for exposure of birds to granular chlorpyrifos 
Table 1 Focal bird species used in the risk assessment of chlorpyrifos

\begin{tabular}{|c|c|c|}
\hline Common name & Scientific name & Feeding preferences \\
\hline Abert's towhee & Pipilo aberti & Insects and seeds from the ground \\
\hline American crow & Corvus brachyrhynchos & Omnivorous and opportunistic ground feeder \\
\hline American robin & Turdus migratorius & Mainly insects and fruit \\
\hline Blue grosbeak & Passerina caerulea & Mainly insects \\
\hline Common pheasant & Phasianus colchicus & $\begin{array}{l}\text { Agricultural grains and other vegetation, } \\
\text { insects, and seeds }\end{array}$ \\
\hline Dickcissel & Spiza americana & Ground-dwelling arthropods and seeds \\
\hline Horned lark & Eremophilia alpestris & $\begin{array}{l}\text { Almost entirely seeds in the winter months, but } \\
\text { also ground-dwelling insects in the spring, } \\
\text { summer and fall }\end{array}$ \\
\hline Indigo bunting & Passerina cyanea & Seeds, berries, and insects gleaned from foliage \\
\hline Killdeer & Charadrius vociferous & $\begin{array}{l}\text { Almost entirely arthropods with a small } \\
\text { amount of seeds }\end{array}$ \\
\hline Mourning dove & Zenaida macroura & Only seeds \\
\hline Northern bobwhite & Colinus virginianus & Insects and seeds \\
\hline Red-winged blackbird & Agelaius phoeniceus & Insects and seeds \\
\hline Vesper sparrow & Pooecetes gramineus & Grasses, seeds and foliage-dwelling insects \\
\hline Western meadowlark & Sturnella neglecta & $\begin{array}{l}\text { Mainly insects with a small amount of seeds } \\
\text { and grains }\end{array}$ \\
\hline
\end{tabular}

\subsection{Focal Species}

The focal bird species selected for the refined avian risk assessment commonly occur in and around areas where CPY may be applied and have adequate data to quantify their foraging behavior and diets (Table 1). They have a range of body mass and are insectivorous, granivorous, or both. Each of the focal species is described in more detail in SI Appendix 1.

\subsection{Exposure Scenarios}

Each focal species was included in a number of exposure scenarios (Tables 2 and 3). The refined assessment focused on application of Lorsban Advanced (the flowable formulation) to the following crops: alfalfa, almond, apple, broccoli, cherry, corn, grape, grapefruit, orange, pecan, soybean, and sweet corn, and application of Lorsban $15 \mathrm{G}$ (the granular formulation) to broccoli, corn, onion, peanut, sugar beet, sunflower, sweet corn, and tobacco. These use patterns are inclusive of the range of application rates, methods, regions, and timing on the Lorsban Advanced and $15 \mathrm{G}$ labels (Solomon et al. 2014). In all of the modeling simulations, we assumed that the maximum application rates and minimum re-treatment intervals permitted on the Lorsban Advanced and 15G labels were used (Tables 2 and 3). The most important use patterns in terms of mass of CPY applied are included in the refined avian 


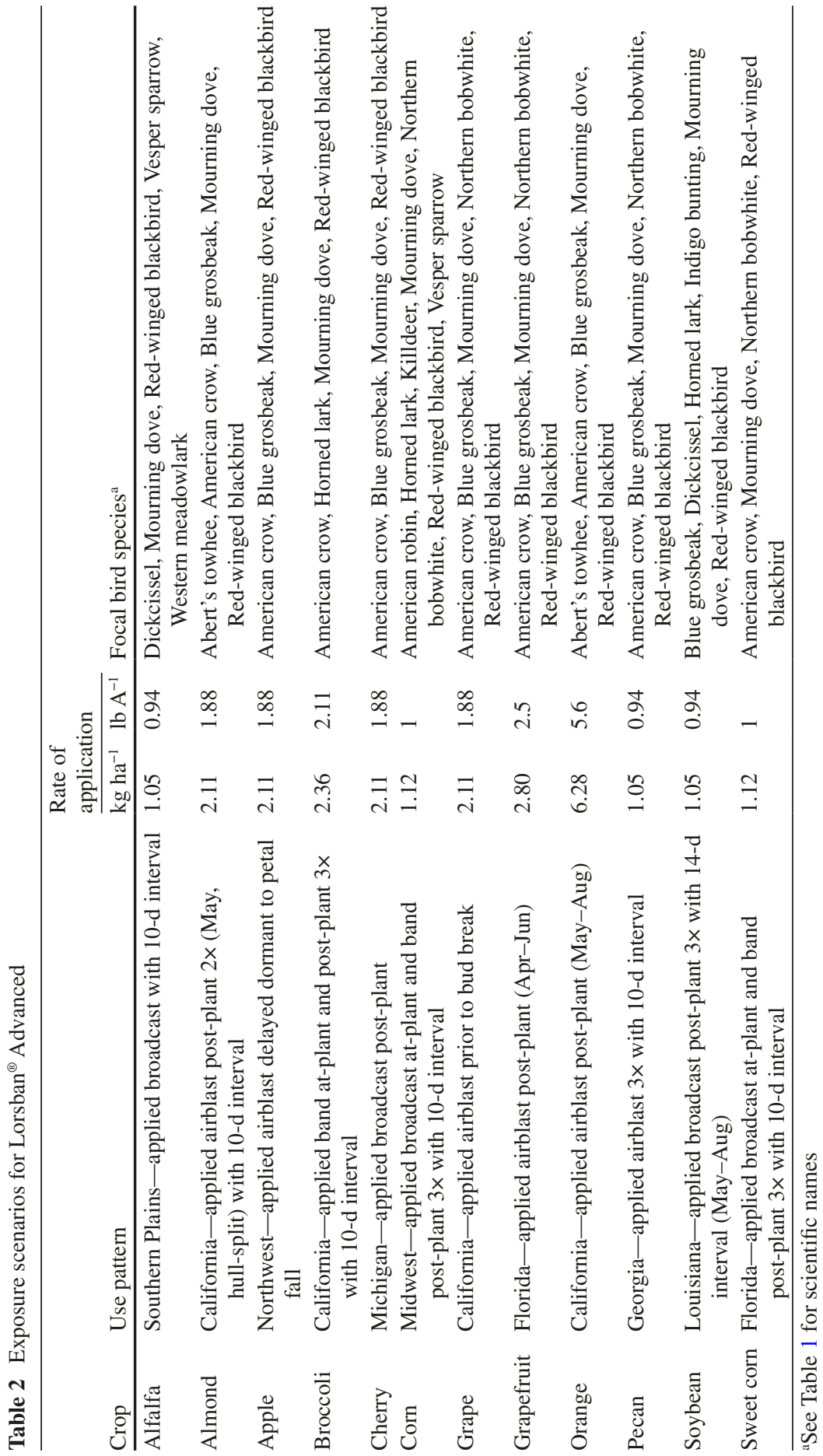


Table 3 Exposure scenarios for Lorsban ${ }^{\circledR} 15 \mathrm{G}$

\begin{tabular}{|c|c|c|c|c|}
\hline \multirow[b]{2}{*}{ Crop } & \multirow[b]{2}{*}{ Use pattern } & \multicolumn{2}{|c|}{$\begin{array}{l}\text { Rate of } \\
\text { application }\end{array}$} & \multirow[b]{2}{*}{ Focal bird species ${ }^{\mathrm{a}}$} \\
\hline & & $\mathrm{kg} \mathrm{ha}^{-1}$ & $\mathrm{lb} \mathrm{A}^{-1}$ & \\
\hline Broccoli & $\begin{array}{l}\text { California—applied T-band } \\
\text { at-plant }\end{array}$ & 2.52 & 2.25 & $\begin{array}{l}\text { Horned lark, Red-winged blackbird, } \\
\text { Mourning dove }\end{array}$ \\
\hline \multirow{2}{*}{$\begin{array}{l}\text { Corn and } \\
\text { sweet } \\
\text { corn }\end{array}$} & \multirow{2}{*}{$\begin{array}{l}\text { Midwest-applied T-band } \\
\text { or in-furrow at-plant; } \\
\text { applied broadcast or } \\
\text { in-furrow postplant }\end{array}$} & 1.46 & 1.3 & \multirow{2}{*}{$\begin{array}{l}\text { Horned lark, Red-winged blackbird, } \\
\text { Mourning dove, Northern } \\
\text { bobwhite, Common pheasant }\end{array}$} \\
\hline & & 1.12 & 1 & \\
\hline Onion & $\begin{array}{l}\text { Pacific northwest—applied } \\
\text { in-furrow at-plant }\end{array}$ & 1.12 & 1 & $\begin{array}{l}\text { Horned lark, Red-winged blackbird, } \\
\text { Mourning dove }\end{array}$ \\
\hline Peanut & $\begin{array}{l}\text { Southeast—applied band } \\
\text { postplant }\end{array}$ & 4.48 & 4 & $\begin{array}{l}\text { Horned lark, Red-winged blackbird, } \\
\text { Mourning dove, Northern } \\
\text { bobwhite }\end{array}$ \\
\hline Sugarbeet & $\begin{array}{l}\text { Midwest—applied broadcast } \\
\text { at-plant }\end{array}$ & 1.12 & 1 & $\begin{array}{l}\text { Horned lark, Red-winged blackbird, } \\
\text { Mourning dove, Northern } \\
\text { bobwhite, Common pheasant }\end{array}$ \\
\hline Sunflower & $\begin{array}{l}\text { Midwest—applied T-band } \\
\text { at-plant }\end{array}$ & 1.45 & 1.3 & $\begin{array}{l}\text { Horned lark, Red-winged blackbird, } \\
\text { Mourning dove, Northern } \\
\text { bobwhite, Common pheasant }\end{array}$ \\
\hline Tobacco & $\begin{array}{l}\text { Southeast-applied broadcast } \\
\text { preplant with incorporation }\end{array}$ & 2.24 & 2 & $\begin{array}{l}\text { Horned lark, Red-winged blackbird, } \\
\text { Mourning dove, Northern } \\
\text { bobwhite }\end{array}$ \\
\hline
\end{tabular}

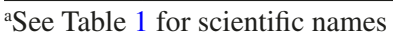

assessments for the two formulations. Applications of Lorsban Advanced can be made up to a rate of $6.3 \mathrm{~kg}$ ai ha $\mathrm{h}^{-1}\left(5.6 \mathrm{lb}_{\mathrm{ai}} \mathrm{A}^{-1}\right)$ (oranges in California) with a maximum of four applications (alfalfa) per season. Only one application of Lorsban $15 \mathrm{G}$ can be made per season with a maximum application rate of $4.5 \mathrm{~kg}^{\mathrm{ai}} \mathrm{ha}^{-1}$ (4 $\mathrm{lb}$ ai $\mathrm{A}^{-1}$ ) (peanut). Lorsban Advanced is generally applied by broadcast, airblast, or banded methods, and Lorsban $15 \mathrm{G}$ is applied by T-band, in-furrow, or broadcast methods. For each use-pattern, a "high use" region of North America was determined from regional sales and use data provided in Gomez (2009). Focal species that would likely be in the treated areas for each use and region were selected by reviewing their ranges, preferred habitats, and patterns of seasonal migrations (see SI Appendix 1). The resulting exposure scenarios are shown in Tables 2 and 3.

\subsection{Analysis Plan}

The refined assessments of risks of Lorsban Advanced and Lorsban 15G to birds were conducted in three phases: assessment of exposure, assessment of effects, and characterization of risks. The following sections outline the analysis plan for Lorsban Advanced (the flowable formulation) and Lorsban 15G (the granular formulation). 
Exposure assessment-Lorsban Advanced. The model used in the assessment of exposure for birds was a refinement of EPA's Terrestrial Investigation Model (TIM) (USEPA 2005, 2008) and is known as the Liquid Pesticide Avian Risk Assessment Model (LiquidPARAM). Version 1 of TIM (TIM v1) estimates the fate of each of 20 birds on each of 1,000 fields following an acute exposure (USEPA 2005). TIM v1 is a species-specific model that estimates risks over a defined exposure window of 7-d. The time-step in the model is $12 \mathrm{~h}$. The spatial scale is the treated field where the field and surrounding area are assumed to meet the habitat requirements of a defined cohort of individuals for each focal species. Pesticide contamination of edge or adjacent habitat from drift is assumed to be zero. Version 2 of TIM (USEPA 2008) is similar to TIM v1 except that it has a 1-h time step and includes a more refined puddle exposure algorithm as well as screening-level algorithms for dermal and inhalation exposure.

Major components included in TIM are: (1) Food preferences of selected focal species; (2) Daily ingestion rates of food and water which are randomly assigned from species-specific body mass distributions; (3) Frequency of feeding and drinking on the treated field; (4) Water sources, including dew and puddles; (5) Distributions of residues on food items and in on-field water sources as a function of application rate; (6) Degradation rates of food and water residues over time; and (7) Interspecies distribution-based estimates of dose-response acute toxicity curves for focal species when laboratory-derived toxicity estimates are not available, or the dose-response curve derived from laboratory toxicity tests for focal species (see SI Appendix 2 for additional details on model structure).

For each simulated bird, values are randomly selected for the input parameters in TIM required to estimate exposure. The estimated risk of lethality for each individual bird is calculated from the dose-response curve. Once the fate of an individual on a particular field is determined (i.e., dead or alive), a new individual is carried through the same process. This process is repeated for a total of 20 individuals on the field. The model then moves to the next field. This outer loop continues for a sample size of 1,000 fields, which results in a risk estimate for a total of 20,000 birds on treated fields.

LiquidPARAM shares some of the similar basic structure of TIM (e.g., each model estimates the fate of each of 20 birds on each of 1,000 fields). However, several important refinements have been made and are briefly described below. A more detailed description is given in SI Appendix 3, Sect. 1.

In TIM, concentrations in dietary items within a field are randomly selected from distributions at each time step. Often this leads to situations where concentrations increase several-fold, 4 or more days after application. This situation seems unlikely in normal use given the fairly short half-life of CPY in the field. LiquidPARAM assumes that factors causing variation in concentrations of CPY on dietary items are relatively small within a field at a particular time step relative to those factors that cause variation between fields. Factors affecting relationships between rate of application and concentrations of pesticides on dietary items include: ambient temperature, wind speed, field slope, soil type, rainfall patterns, applicator experience, and type of equipment used to apply the spray. These factors vary only slightly 
within a field, but can be quite variable among fields within a broad region of the United States. Thus, for each field, LiquidPARAM randomly chooses an initial concentration for each dietary item and then these concentrations decline in the field over time according to the degradation rate for that dietary item. When the model proceeds to the next field, new initial concentrations are randomly selected. The process is repeated for 1,000 fields.

TIM assumes that bands occupy $17 \%$ of each field and furrows 5\% of each field. However, these factors vary among crops. LiquidPARAM has been customized to have crop-specific row widths and spacing.

TIM uses older allometric equations provided by Nagy (1987) to estimate free metabolic rate. LiquidPARAM uses the more up-to-date allometric equations from Nagy et al. (1999). LiquidPARAM also accounts for uncertainty in estimates of free metabolic rate arising from error due to lack of model fit, while TIM does not.

TIM also does not account for the avoidance behavior that has been observed by birds following initial exposure to CPY (Bennett 1989; Wildlife International 1978). LiquidPARAM accounts for this behavior. Further, TIM only simulates acute exposure following a single pesticide application. LiquidPARAM can simulate both acute and chronic exposures following multiple pesticide applications.

Exposure assessment-Lorsban 15G. Previously, a simulation model was developed that estimated exposure and risk for various bird species that are potentially exposed to the granular formulation of aldicarb (Moore et al. 2010b, c). That model, referred to as the Granular Pesticide Avian Risk Assessment Model (GranPARAM), includes input variables such as: proportion time in the field, rates of ingestion of grit, attractiveness of pesticide granules compared to natural grit, and proportion of soil particles in the grit size range preferred by birds. For input variables that are uncertain, variable, or both, frequency distributions are used rather than point estimates. Monte Carlo analysis is then performed to propagate input variable uncertainties through the exposure model. Similar to LiquidPARAM, GranPARAM determines the fate of 20 randomly chosen birds on each of 1,000 randomly selected fields for the use pattern and region of interest. GranPARAM was revised to be specific to CPY for this refined avian risk assessment (see Sect. 4 and SI Appendix 3, Sect. 2).

Effects assessment. Effects data can be characterized and summarized in a variety of ways, ranging from benchmarks designed to be protective of most or all species to dose-response curves for the focal species of interest. When toxicity data are lacking for a focal bird species, a species sensitivity distribution (SSD) can be used to give an indication of the risk range by varying the dose-response curve from that of a sensitive species to that of a tolerant species. This approach was used by EPA (USEPA 2005) in their avian risk assessment for carbofuran. The SSD approach was also used in this assessment, except when toxicity data were available for the focal species of interest (see Sect. 5).

Effects associated with survival of juveniles or adults were the preferred measure of acute effect because this endpoint was judged to be the most appropriate based on the mode of toxic action of CPY. Gavage studies were used in preference to dietary studies because of problems in estimating dose when avoidance of treated 
food is a factor. Because flowable CPY may be applied up to four times per growing season, chronic risk was also estimated for that formulation. For the chronic assessment, preferred metrics included the most sensitive of the population-relevant endpoints, viz., survival, growth and reproduction.

The following decision criteria were used in deriving effects metrics for each focal species: (1) If a toxicity study with five or more treatments was available for the focal species or a reasonable surrogate, then a dose-response curve was derived for that species; (2) If multiple toxicity studies that followed a similar protocol and together had five or more treatments were available for the focal species or a reasonable surrogate, then a dose-response curve was derived for that species; (3) For untested focal species, an SSD was derived.

Without toxicity data for a focal species, there is uncertainty regarding the sensitivity of that species to CPY. To deal with this uncertainty, the SSD was used to bound the risk estimates (i.e., assume 5th and 95th centile sensitivity on the SSD) and to estimate median risk (i.e., assume 50th centile sensitivity on the SSD) (USEPA 2005). Dose-response curves were then derived for low (95th centile), median (50th centile) and high (5th centile) sensitivity species by using a distribution of the available $\mathrm{LD}_{50}$ data and measured dose-response curve slopes. Because insufficient bird species have been tested for chronic exposure, the most sensitive effects metrics were assumed for all focal species.

Each toxicity study was evaluated, and acceptable studies met the following criteria: (1) Single contaminant exposure only; (2) Gavage (acute) or dietary (chronic) route of exposure; (3) Ecologically-significant endpoint (e.g., survival, reproduction, growth); (4) Adequate statistical design (e.g., five or more treatments including controls, responses spanning most of the range of $0-100 \%$ effect including at least one treatment with a partial response) to estimate toxic effect doses; and (5) Study employed acceptable laboratory practices or was previously accepted by EPA (USEPA 2009). Studies that did not meet the above criteria were not used to derive effects metrics.

Risk characterization. Three lines of evidence were used to characterize risks of CPY to birds: (1) Modeling of exposure and effects; (2) Information available from field studies; and (3) Information available from incident reports.

Risk curves were derived for each exposure scenario and focal bird species by determining the percentages of fields that had $\geq 5 \%$ mortality ( $\geq 1 / 20$ dead birds per field), $\geq 10 \%$ mortality ( $\geq 2 / 20$ dead birds per field), $\geq 15 \%$ mortality ( $\geq 3 / 20$ dead birds per field), .., 100\% mortality (20/20 dead birds per field). The result was a plot of probability of exceedence versus magnitude of effect. Similar approaches have been used in ecological risk assessments performed for the EPA at the Calcasieu Estuary, Louisiana, the Housatonic River, Massachusetts (USEPA 2002, 2004a) and by others assessing the ecological risk of pesticides (Giddings et al. 2005; Moore et al. 2010a, b, c; Solomon et al. 2001). In this assessment, area under the risk curve (AUC) was estimated for each combination of focal species and exposure scenario. AUC is the area under the curve divided by the sum of the AUC and the area above the curve, with the result multiplied by 100 . The AUC was used to 
Fig. 3 Risk curves defined by risk products (RP) of 0.25 , 2 and $10 \%$

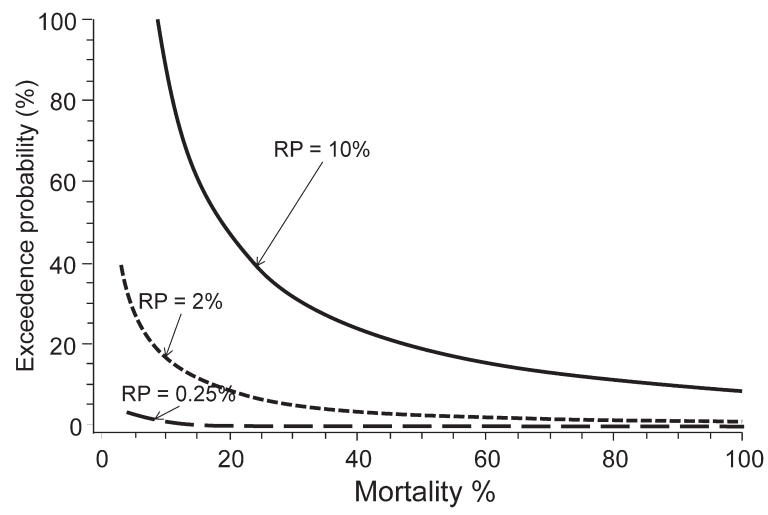

categorize risk as follows: (1) If the area under the risk curve was less than the AUC associated with the curve produced by risk products (risk product=exceedence probability $\times$ magnitude of effect) of $0.25 \%$ (e.g., $5 \%$ exceedence probability of $5 \%$ or greater effect $=0.25 \%$ ), then the risk was categorized as de minimis. The AUC for risk products of $0.25 \%$ is $1.75 \%$; (2) If the AUC was equal to or greater than $1.75 \%$, but less than $9.82 \%$ (i.e., the AUC for risk products of $2 \%$ ), then the risk was categorized as low; (3) If the AUC was equal to or greater than $9.82 \%$, but less than $33 \%$ (i.e., the AUC for risk products of $10 \%$ ), then the risk was categorized as intermediate; and (4) If the AUC was equal to or greater than $33 \%$, then the risk was categorized as high. The risk curves defined by risk products of $0.25,2$ and $10 \%$ are shown graphically in Fig. 3.

Categories of risk were based on a rationale described previously (Moore et al. 2010a, b) and included several considerations: (1) Losses of small numbers of individuals from a local population should not adversely affect the population (Giddings et al. 2005; Moore 1998). One of the foundations of hierarchy theory (Allen and Starr 1982) is that effects at lower levels of ecological organization (e.g., organism level) are not necessarily transmitted to higher levels of ecological organization (e.g., population level); (2) Although there are exceptions, an adverse effect level of $10 \%$ is unlikely to be ecologically significant to a local population. Such an effect generally cannot be reliably confirmed by field studies (Moore 1998; Suter et al. 2000); (3) Based on an analysis of EPA regulatory practice, Suter et al. (2000) concluded that decreases in an ecological assessment endpoint of less than $20 \%$ are generally acceptable; (4) The curve corresponding to a risk product of $2 \%$ passes through the points corresponding to a very low probability (i.e., 10\%) of $20 \%$ or greater effect, and a low probability (i.e., 20\%) of $10 \%$ or greater effect. Thus, based on the considerations described above, if risk products are generally less than the $2 \%$ boundary for an exposure scenario, then it can almost certainly be considered a low risk scenario; (5) The curve corresponding to a risk product of $10 \%$ passes through the points corresponding to a median probability (i.e., $50 \%$ ) of $20 \%$ or greater effect and a $20 \%$ probability of $50 \%$ or greater effect. In this assessment, exposure scenarios with risk products generally above the $10 \%$ boundary were 
considered to be high risk scenarios because there was a low to median probability of detectable and possibly major impacts on local bird populations. Scenarios with risk curves generally between the low and high boundaries were judged to be intermediate risk scenarios; (6) When there was a very low likelihood of a scenario affecting a focal bird species, risk was categorized as de minimis. A 5\% probability of exceeding $5 \%$ adverse effect lies on the curve defined by the risk product equal to $0.25 \%$. The AUC associated with the risk curve defined by risk products of $0.25 \%$ (AUC $=1.75 \%$ ) was thus used as the upper boundary for the category of de minimis risk. The percent protection level was also calculated for each exposure scenario and focal species. Protection level (\%) is equal to the number of surviving birds divided by the number of birds included in the model run ( 20 birds per field $\times 1,000$ fields $=20,000$ birds) times 100 .

The risk characterization also incorporated available field study results and incident reports into the assessment of the avian risks associated with legal labeled uses of CPY.

\section{Exposure Assessment for Flowable Chlorpyrifos}

The development of a probabilistic assessment model for risks of flowable pesticides to birds began with the formation of the Ecological Committee on FIFRA Risk Assessment Methods (ECOFRAM). ECOFRAM was tasked with identifying and developing probabilistic tools and methods for ecological risk assessments under the FIFRA regulatory framework. Conclusions and recommendations of the ECOFRAM workgroup on avian exposure models were summarized in the Draft Terrestrial Workgroup Report (ECOFRAM 1999). Subsequently, EPA formed an internal committee to develop tools (e.g., Terrestrial Investigation Model) and to develop an approach for incorporating the ECOFRAM workgroup conclusions and recommendations. That approach was evaluated and endorsed by a United States Environmental Protection Agency (USEPA) Scientific Advisory Panel in 2000 (SAP 2000).

The pilot version of the Terrestrial Investigation Model, version 1 (TIM v1) was developed to evaluate a model pesticide called ChemX. Based on recommendations and comments of another SAP (SAP 2001), the EPA began to refine TIM v1 and produced a draft version of TIM version 2 (TIM v2). TIM v2 was evaluated by the SAP (SAP 2004) and subsequently refined. TIM v1 was the model used by EPA (USEPA 2005) to estimate the risks of a flowable carbofuran formulation to avian species that forage in treated fields and is summarized in SI Appendix 2.

\subsection{Rationale for Developing LiquidPARAM}

Much of the basic structure of the Liquid Pesticide Avian Risk Assessment Model (LiquidPARAM) was based upon TIM v1 and v2. Since the release of TIM, studies 
have taken place that can be used to refine components of the model. These studies address areas not included in TIM, such as avoidance behavior of birds exposed to CPY (Bennett 1989; Wildlife International 1978) and measured concentrations of CPY on dietary items. Thus, one reason for developing LiquidPARAM was to expand the model structure of TIM to accommodate new information. Changes to TIM were also required to address the recommendations of the SAPs (SAP 2001, 2004) that reviewed the TIM model. Where possible, LiquidPARAM incorporated recommendations of the SAP (SAP 2001, 2004) including, for example:

- Addition of many new focal species and use patterns to ensure better representation of the bird community that forages in agroecosystems.

- Use of a 1-h time step in LiquidPARAM, instead of the 12-h time step used in TIM v1. TIM v2 also moved to a 1-h time step. This refinement was considered necessary to account for the changes in avian foraging behavior, avoidance behavior, and clearance of the pesticide that occur throughout the day.

- For each time step in TIM v1 and v2, the model randomly determines whether a bird is on or off the treated field. The SAP (SAP 2001) felt that this approach misrepresented how birds forage in agroecosystems. LiquidPARAM allows birds to forage on and off fields in each time step. The model also accounts for between-field differences in foraging behavior of bird populations that have been observed due to factors affecting the relative attractiveness of treated fields to birds (e.g., type of edge habitat, availability of cover, etc.). Relative attractiveness of fields to birds can vary dramatically between treated areas.

- The SAP (SAP 2001) observed that TIM v1 confused inter- and intra-field variation by using dietary residue distributions that included both sources of variation. Residue levels in each field in TIM v1 relied on the same distributions, as is the case in TIM v2. However, one would expect larger differences in mean concentrations of residues between fields than within fields because of differences in soil type and topography, operator skill, type of application machinery, etc. Further, birds spatially and temporally average their dietary exposures within fields because they generally make multiple foraging trips within any given 1 -h time step (see Sect. 1.2 in SI Appendix 3). LiquidPARAM incorporates a model structure that accounts for the expected variation between fields in mean concentrations of residues in dietary items.

- LiquidPARAM incorporates an avoidance behavior component that was suggested by the SAP (SAP 2001) as being a potentially important factor in reducing risk (see EFSA 2008).

- The SAP (SAP 2001) noted that acute oral studies do not account for the effect of the dietary matrix on adsorption rate of pesticides by birds. LiquidPARAM can account for the difference in toxicity to birds of flowable pesticide administered in water versus a dietary matrix if such data are available.

- Because flowable CPY may be applied up to four times per season, there is a potential for chronic exposure. As a result, LiquidPARAM has been extended to a 60-d model that can be used to estimate chronic risks potentially arising from multiple applications. 
- Finally, the SAP (SAP 2001) stated that field validation of a model, particularly a complex model, is critical. This has yet to be done for TIM v1 or v2. An evaluation of model performance was previously done for LiquidPARAM with flowable carbofuran, the results of which are discussed in SI Appendix 3.

It was not possible to incorporate all of the recommendations of the SAP (US EPA SAP 2001, 2004) because information is still lacking in several areas. For example, the SAP (SAP 2001) expressed concern that TIM equates proportion time spent in treated fields as the proportion of diet obtained from the treated fields. The data required to act on this recommendation are not available for North American bird species that forage in agroecosystems.

The SAP (SAP 2001) also noted that there is considerable uncertainty regarding how birds obtain drinking water from treated fields and other nearby habitats. As in TIM v1, LiquidPARAM includes three drinking water scenarios (dew, dew plus puddles on day of application, and dew plus puddles on the day after application). The Panel (SAP 2001) concluded that this approach was reasonable, but recommended that further research be undertaken on: (1) the linkage between time on the field and amount of water consumed, (2) puddle persistence, (3) concentrations in dew and puddles, and (4) consumption of dew by different bird species. The SAP (SAP 2001) noted that field telemetry studies combined with laboratory bird behavior studies could provide the needed data. Because such studies have not yet been conducted, and because drinking water appears to be a minor source of exposure for flowable CPY (see the results of the sensitivity analysis in SI Appendix 3, Sect. 1.4), LiquidPARAM retains the same drinking water scenarios as exist in TIM v1. A graphical description of the structure of the LiquidPARAM model is illustrated in Fig. 4 and details of the model are provided in SI Appendix 3

\subsection{Description of the Structure of the LiquidPARAM Model}

For acute exposure, LiquidPARAM estimates the maximum retained dose that occurs over a period of 60-d following initial pesticide application in each of 20 birds on each of 1,000 fields (Fig. 4). The model can accommodate up to three applications at intervals specified by the user. The model has a 1-h time step. For each bird, a standard normal $\mathrm{Z}$ score is calculated for the maximum retained dose. This $\mathrm{Z}$ score determines how extreme the exposure is relative to the appropriate $\mathrm{LD}_{50}$ using a log-probit dose-response relationship. The $\mathrm{Z}$ score is then compared to a randomly selected value from a uniform distribution with a range of $0-1$. If the $Z$ score for exposure exceeds the randomly drawn value from the uniform distribution the bird dies. Otherwise, it survives (Fig. 4).

For species lacking acceptable acute oral toxicity data (all focal species except the northern bobwhite, C. virginianus, and red-winged blackbird, Agelaius phoeniceus, for CPY), a species sensitivity distribution (SSD) approach is used to generate the effects metrics. With this approach, a regression analysis is first conducted to 


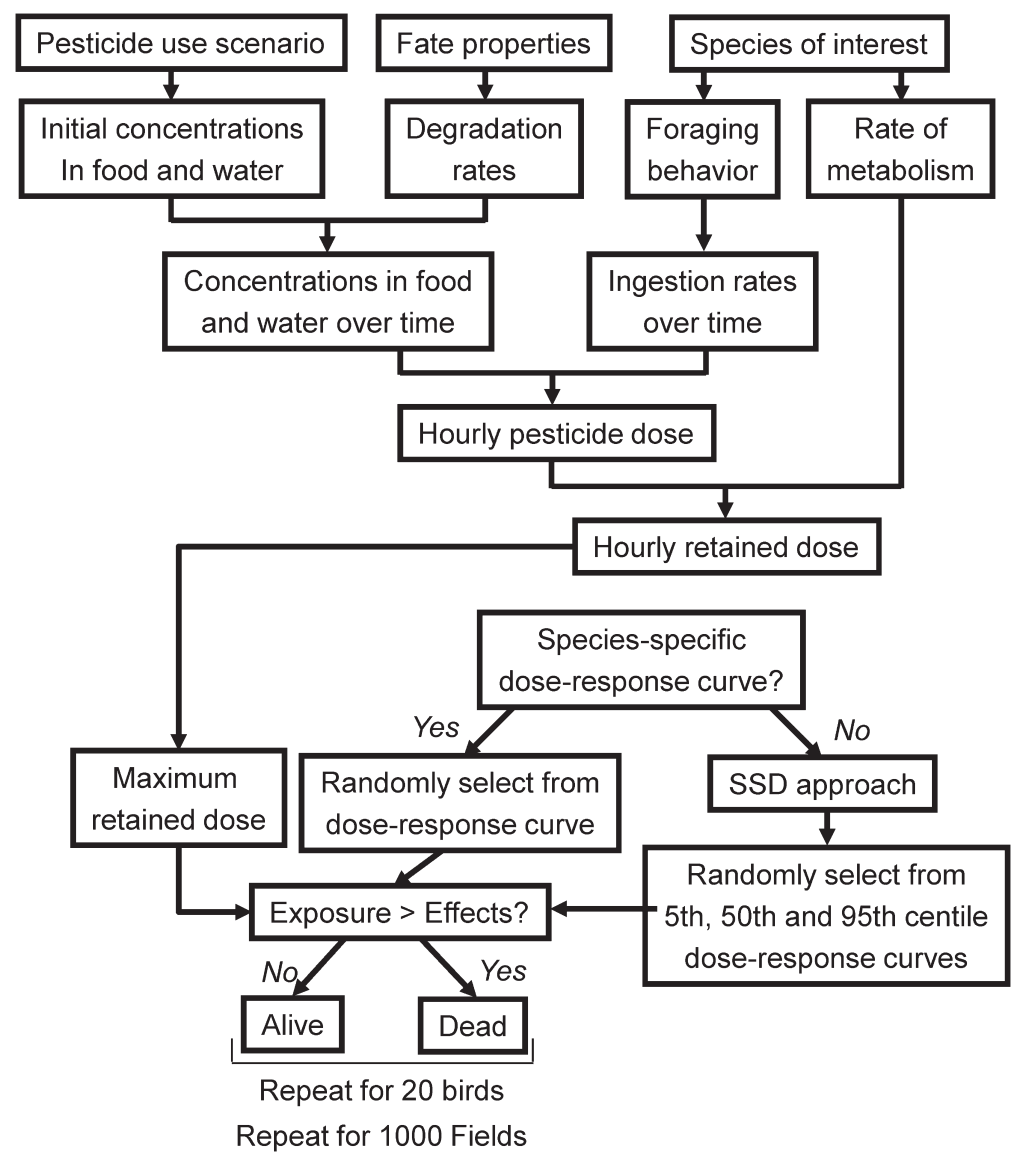

Fig. 4 Components of LiquidPARAM

quantify the relationship between dose and proportion species affected as determined by their $\mathrm{LD}_{50} \mathrm{~S}$. Hypothetical dose-response curves are then derived for species of high (5th centile species on the SSD), median (50th centile species) and low (95th centile species) sensitivity. The 5th, 50th and 95th centile $\mathrm{LD}_{50} \mathrm{~s}$ are combined with the average slope for tested bird species to parameterize the three hypothetical dose-response curves assuming an underlying log-probit distribution. Section 5 describes the assessment of acute effects in detail.

For chronic exposure, total daily intake (TDI) is estimated for each day in the $60-\mathrm{d}$ model run. TDI is averaged over a period equal to the duration from which the most sensitive effects metric was derived (e.g., gestation period for number of eggs laid). The maximum rolling average from the 60-d model run for each bird is then compared to a randomly drawn TDI from the appropriate chronic dose-response curve, if available, to determine if the bird is adversely affected and, if so, magnitude of effect. In the absence of a chronic dose-response curve, as is the case for CPY, 
LiquidPARAM calculates the probability of maximum average TDI across all birds exceeding the chronic NOEL and the corresponding probability for exceeding the LOEL. Section 5 describes the assessment of chronic effects in detail.

\section{Exposure Assessment for Granular Chlorpyrifos}

The Granular Pesticide Avian Risk Assessment Model (GranPARAM) was used to estimate exposure and fate of birds as a result of consuming pesticide granules in CPY-treated agricultural fields. The model as originally described (Moore et al. $2010 \mathrm{~b}, \mathrm{c}$ ) has been updated for this assessment.

GranPARAM simulates the grit ingestion behavior of individual birds and determines how many pesticide granules and the associated dose each bird ingests during the 24-h period immediately following CPY application. Each bird in a GranPARAM simulation is assumed to be actively foraging for grit in and around the agricultural field to which CPY has been applied. The scheme that GranPARAM follows to model granule ingestion behavior is depicted in Fig. 5.

In GranPARAM, each bird is randomly assigned a daily grit intake rate from a large database of grit counts for the species being considered and estimated grit retention rate. This step defines the number of medium- and coarse-sized particles (i.e., particles in the same size range as Lorsban $15 \mathrm{G}$ granules) that the individual ingests during the peak day of the simulation. For CPY, the peak day was assumed to be the $24 \mathrm{~h}$ immediately following application. The work of Stafford et al. (1996) and Stafford and Best (1997) showed that most pesticide granules are incorporated into soil, and thus unavailable to birds, within 1-d of application. Rainfall accelerates this process (Stafford and Best 1997). GranPARAM relies on estimates of granule counts on the soil surface immediately after application, which clearly represents the maximum possible exposure for birds (Solomon et al. 2001).

Each site of application of the granular formulation is randomly assigned a soil texture (e.g., Silt-Loam) with a probability equal to the occurrence of that texture fraction in the crop-capable acreage in the region of interest. The database in the model was originally for corn, but has been expanded to include other crops and areas to which CPY is applied. Once the soil texture category is assigned, the application site is then randomly assigned a specific soil particle size profile (\% of soil mass represented by various particle size categories) from a large soils database of measurements. This step defines the levels of medium- and coarse-sized sand particles available as natural grit.

For each exposure scenario (Table 3), the method of application, rate of application, incorporation efficiency, bird species, region of interest, and other aspects of the analysis included in the simulation were defined (Fig. 5). The rate of application of CPY defines the relative numbers of medium- and coarse-sized granules applied. The method of application (e.g., in-furrow, band, broadcast) determines the spatial placement of these granules and the number available as a source of particles to birds. The choice of bird species determines the number of particles ingested. 


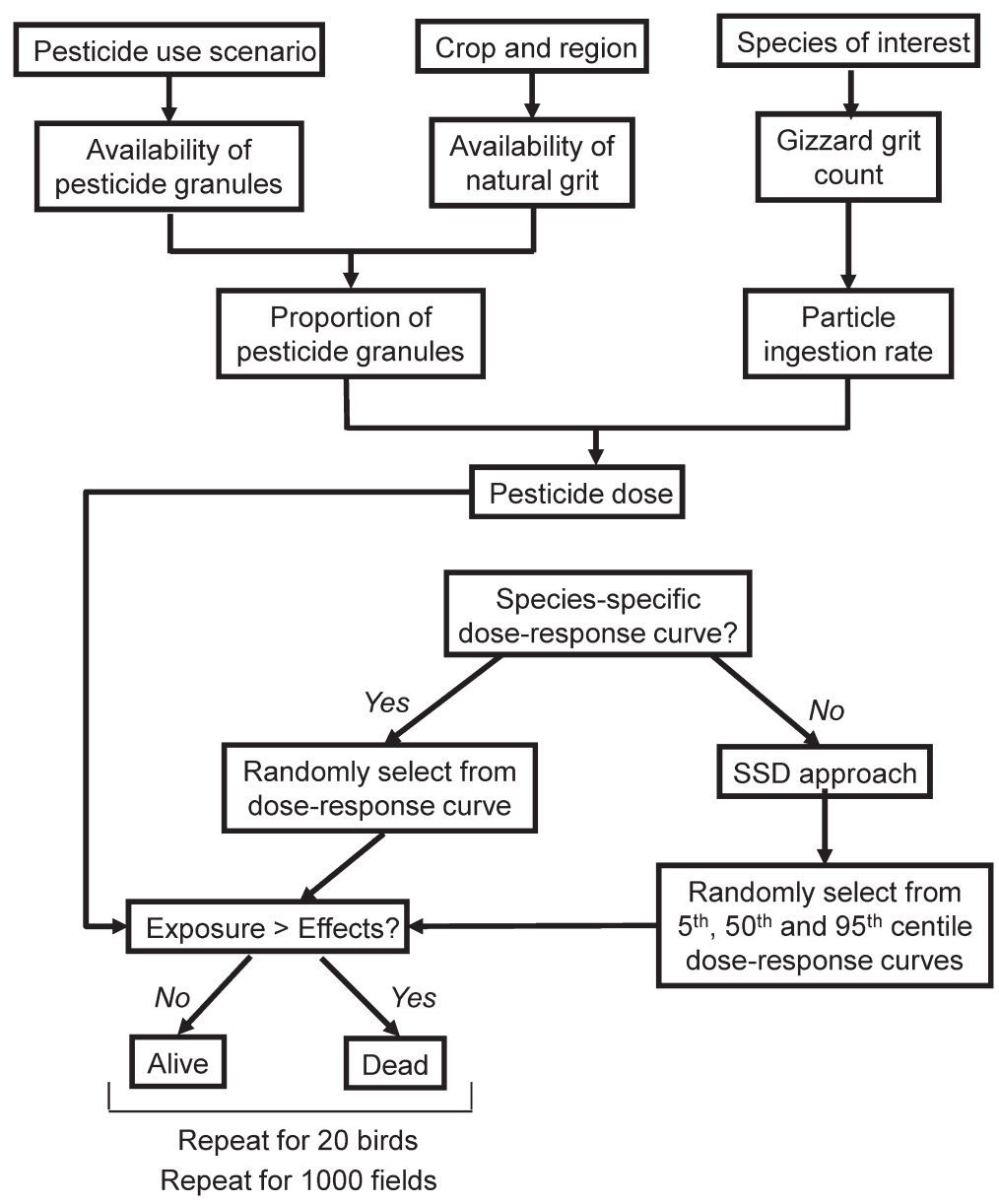

Fig. 5 Components of GranPARAM

Each time a bird feeding in a treated field ingests a particle, the particle is either a granule or a piece of natural grit. The default assumption of the model is that birds forage for particles within each spatial zone randomly, and therefore the probability, $p$, of selecting a pesticide granule is equal to the relative availability of granules in comparison to natural grit particles of the same size. However, birds may select particles non-randomly and show preference for some types of particles over others (Best and Gionfriddo 1994; Best et al. 1996). In GranPARAM, the user has the option to input the relative preference birds have for selecting pesticide granules in comparison to natural grit. If this factor is used, as was the case with CPY, GranPARAM modifies the estimate of $p$ accordingly. Birds prefer sand for grit consumption and thus strongly avoid Lorsban $15 \mathrm{G}$ granules because of its clay-based formulation (see SI Appendix 3, Sect. 2.1 for additional details). Once $p$ is defined, the number of Lorsban $15 \mathrm{G}$ granules ingested during the day following application 
is determined by randomly sampling from a binomial distribution defined by $N$ (number of particles ingested that could be either granules or natural sand) and $p$. This calculation is made separately for medium- and coarse-sized pesticide granules, and for spatial zones of the field that differ from one another in either the relative availability of granules or relative use by birds (e.g., end rows, field margin, field center). The number of particles the bird obtains from a given zone $(N)$ is estimated from the zone's relative size and use by birds.

The version of GranPARAM described herein estimated exposure to 20 birds on each of 1,000 fields, as previously described for LiquidPARAM. The 1,000 fields were intended to represent the range of soil characteristics for the crop and region of interest. In GranPARAM, characteristics of birds such as grit counts in their gizzard and proportion of time they forage in treated fields are chosen randomly from distributions. Thus, individuals on fields differ from one another and the model is designed to explicitly incorporate the variation observed in nature. Similarly, characteristics of fields such as differences in size distribution and composition of soil are randomly chosen from distributions in GranPARAM. This approach ensures that the variability in field soils observed in nature is reflected in the model.

The outputs from the exposure portion of GranPARAM are estimated acute doses for each of 20 birds on each of 1,000 fields. The effects and risk components of GranPARAM and LiquidPARAM for acute exposure are the same. The risk output from GranPARAM is a bar chart showing the percentages of fields with 0/20 dead birds, $1 / 20$ dead birds, 2/20 dead birds, etc.

The components of the model and input variables for GranPARAM are described in detail in SI Appendix 3. Simulations were run for each of the exposure scenarios listed in Table 3. All simulations were carried out using Latin Hypercube Sampling in Oracle Crystal Ball (2009), Version 7.3.2 with 1,000 trials (i.e., fields) per simulation and 20 birds per field.

\section{Effects Assessment}

Upon ingestion, CPY is rapidly absorbed and undergoes oxidative metabolism to the oxon form, which is the metabolite primarily responsible for toxicity (Testai et al. 2010). Chlorpyrifos inhibits acetylcholinesterase activity causing acetylcholine to accumulate at nerve terminals and neuromuscular junctions, which leads to cholinergic overstimulation (Testai et al. 2010). In birds, CPY poisoning can be detected biochemically as reduced cholinesterase activity in plasma and brain tissues (Cairns et al. 1991; Parsons et al. 2000; Timchalk 2010). A gavage study with northern bobwhite (C. virginianus) found reduced brain cholinesterase activity at concentrations of $47 \mathrm{mg}$ ai $\mathrm{kg}^{-1}$ bwt of CPY and greater (Cairns et al. 1991). Cholinesterase activity remained inhibited for at least $24-48 \mathrm{~h}$ thereafter.

The following sections present a review of the available acute and chronic effects studies and the derivation of the acute and chronic effects metrics that were used to characterize risks to birds from the use of CPY. 


\subsection{Acute Toxicity Studies}

Oral gavage and dietary studies have been conducted to determine the acute effects of CPY on birds (Table 4). Data on toxicity of CPY to birds were reviewed previously (Solomon et al. 2001) and in the sections that follow, only studies that have been conducted since that review are discussed.

Hubbard and Beavers (2008) administered CPY by oral gavage at $21.6 \mathrm{mg}$ ai $\mathrm{kg}^{-1}$ bwt to 19 -wk old northern bobwhite (C. virginianus) using corn oil as a vehicle and observed signs of toxicity (Hubbard and Beavers 2008). The effects included a ruffled appearance and lethargy. Signs of toxicity were more prevalent and occurred sooner at higher doses. Reduced consumption of food was observed at doses $\geq 36 \mathrm{mg}$ ai kg-1 bwt. The acute oral $14-\mathrm{d} \mathrm{LD}_{50}$ was $>60 \mathrm{mg}$ ai kg-1 bwt, as only $30 \%$ mortality occurred at this dose, the largest tested. The no-mortality dose was $36 \mathrm{mg}$ ai $\mathrm{kg}^{-1}$ bwt and the NOEL was $13 \mathrm{mg}$ ai $\mathrm{kg}^{-1}$ bwt.

The acute oral toxicity of Lorsban 50W was determined by exposing northern bobwhite (C. virginianus) (Kaczor and Miller 2000). Twenty-two-wk old birds were dosed once with Lorsban 50W (50.5\% purity) and observed for 14-d. Food consumption, body weight, signs of toxicity, and lethality were monitored throughout

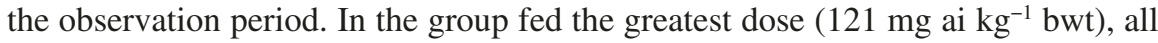
birds died within $24 \mathrm{~h}$ of dosing. During the first day or two following dosing, consumption of food by birds exposed to CPY was less that of the controls. However, rates of food consumption quickly returned to those of control birds and, as a result, there was no significant decrease in body weight over the study period for any of the treatment groups. The most prevalent sign of toxicity was lethality. The only other observed sign of toxicity was lethargy and it usually preceded lethality. Necropsies of dead birds revealed gaseous intestines. The $\mathrm{LD}_{50}$ was $35.9 \mathrm{mg}$ ai $\mathrm{kg}^{-1}$ bwt, the NOEC was $7.6 \mathrm{mg}$ ai $\mathrm{kg}^{-1}$ bwt and the LOEC was $15.2 \mathrm{mg}$ ai $\mathrm{kg}^{-1}$ bwt.

In other studies, the toxicity of CPY in a variety of formulations was evaluated. These formulations included Lorsban 2.5P (2.48\% ai, Brewer et al. 2000b), Lorsban 10.5 LEE (10.5\% ai, Brewer et al. 2000a), GF-1668 (18.7\% ai, Gallagher and Beavers 2006), and Lorsban Advanced (41.1\% ai, Hubbard and Beavers 2008). The lowest $\mathrm{LD}_{50}$ from these studies was $12.6 \mathrm{mg}$ ai $\mathrm{kg}^{-1}$ bwt (Brewer et al. 2000a) and the smallest NOEL was $<4 \mathrm{mg}$ ai $\mathrm{kg}^{-1}$ bwt (Hubbard and Beavers 2008).

To determine the importance of duration of acute exposure on a daily basis, 25-wk old northern bobwhite (C. virginianus) were pre-conditioned to feed during either a 1- or 8-h period each day (Gallagher and Beavers 2007). Following the pre-conditioning period, the birds were offered food treated with CPY for either 1 or $8 \mathrm{~h}$ for $1-\mathrm{d}$. The birds were observed for $7-\mathrm{d}$ after treatment. Rate of food consumption and body mass decreased with increasing dietary concentration of CPY in both treatment groups. Greater toxicity was observed in the group feeding for only $1 \mathrm{~h}$ each day. This result suggests that birds being exposed over an 8 -h period had longer to metabolize and detoxify CPY. $\mathrm{LD}_{50}$ values were $75 \mathrm{mg}^{\mathrm{ai} \mathrm{kg}} \mathrm{kg}^{-1}$ bwt for birds receiving their total dose in $1 \mathrm{~h}$ and $116 \mathrm{mg}^{\mathrm{ai} \mathrm{kg}} \mathrm{kg}^{-1}$ but for those receiving the




Table $4 \mathrm{LD}_{50} \mathrm{~s}$ from acceptable oral gavage studies for chlorpyrifos

\begin{tabular}{|c|c|c|c|c|c|}
\hline Species & Life stage & $\begin{array}{l}\mathrm{LD}_{50} \\
\text { (mg ai } \\
\mathrm{kg}^{-1} \text { bwt) }\end{array}$ & $\begin{array}{l}\text { Probit } \\
\text { slope }\end{array}$ & $\begin{array}{l}\text { SSD } \\
\text { input } \\
\text { value } \\
\end{array}$ & Reference \\
\hline \multirow{2}{*}{$\begin{array}{l}\text { Common grackle } \\
\quad(\text { Quiscalus quiscula })\end{array}$} & Adult & 5.62 & - & \multirow[t]{2}{*}{8.55} & Schafer and Brunton (1979) \\
\hline & Adult & 13 & - & & Schafer and Brunton (1971) \\
\hline \multirow{2}{*}{$\begin{array}{l}\text { Ring-necked pheasant } \\
\text { (Phasianus colchicus) }\end{array}$} & Adult, male & 8.41 & - & \multirow[t]{2}{*}{12.2} & \multirow[t]{2}{*}{ Hudson et al. (1984) } \\
\hline & Adult, female & 17.7 & - & & \\
\hline $\begin{array}{l}\text { Red-winged blackbird } \\
\quad \text { (Agelaius phoeniceus) }\end{array}$ & Adult, male & 13.1 & - & 13.1 & Schafer and Brunton (1979) \\
\hline \multirow{3}{*}{$\begin{array}{l}\text { Japanese quail (Coturnix } \\
\text { japonica) }\end{array}$} & Adult & 13.3 & - & \multirow[t]{3}{*}{15.6} & Schafer and Brunton (1979) \\
\hline & Adult, male & 15.9 & - & & Hudson et al. (1984) \\
\hline & Adult, male & 17.8 & - & & \\
\hline \multirow{2}{*}{$\begin{array}{l}\text { Common pigeon } \\
\quad(\text { Columba livia })\end{array}$} & Adult & 10 & - & \multirow[t]{2}{*}{16.4} & Schafer and Brunton (1979) \\
\hline & Adult & 26.9 & - & & Hudson et al. (1984) \\
\hline $\begin{array}{l}\text { Sandhill crane (Grus } \\
\text { canadensis) }\end{array}$ & Adult, male & $25-50$ & - & 25.0 & Hudson et al. (1984) \\
\hline \multirow{3}{*}{$\begin{array}{l}\text { House sparrow (Passer } \\
\quad \text { domesticus) }\end{array}$} & Adult & 10 & - & \multirow[t]{3}{*}{29.5} & Schafer and Brunton (1979) \\
\hline & Adult, male & 21 & - & & Hudson et al. (1984) \\
\hline & Adult & 122 & 2.3 & & Gallagher et al. (1996) \\
\hline \multirow{2}{*}{$\begin{array}{l}\text { Leghorn chicken (Gallus } \\
\quad \text { domesticus) }\end{array}$} & Chick, male & 32 & - & \multirow[t]{2}{*}{33.4} & McCollister et al. (1974) \\
\hline & Adult & 34.8 & - & & $\begin{array}{l}\text { Miyazaki and Hodgson } \\
\text { (1972) }\end{array}$ \\
\hline $\begin{array}{l}\text { Canada goose (Branta } \\
\text { canadensis) }\end{array}$ & Adult & $40-80$ & - & 40.0 & Hudson et al. (1984) \\
\hline \multirow[t]{2}{*}{ Chukar (Alectoris chukar) } & Adult, female & 60.7 & - & \multirow[t]{2}{*}{60.9} & \multirow[t]{2}{*}{ Hudson et al. (1984) } \\
\hline & Adult, male & 61.1 & - & & \\
\hline \multirow{2}{*}{$\begin{array}{l}\text { Northern bobwhite } \\
\quad \text { (Colinus virginianus) }\end{array}$} & Juvenile & 119 & 3.88 & \multirow[t]{2}{*}{61.7} & Kaczor and Miller (2000) \\
\hline & Adult & 32 & 4.6 & & Hill and Camardese (1984) \\
\hline $\begin{array}{l}\text { California quail } \\
\quad \text { (Callipepla } \\
\text { californica) }\end{array}$ & Adult, female & 68.3 & - & 68.3 & Hudson et al. (1984) \\
\hline $\begin{array}{l}\text { European starling (Sturnus } \\
\quad \text { vulgaris) }\end{array}$ & Adult & 75 & - & 75.0 & Schafer and Brunton (1979) \\
\hline \multirow{2}{*}{$\begin{array}{l}\text { Mallard (Anas } \\
\quad \text { platyrhynchos) }\end{array}$} & Adult, female & 75.6 & - & \multirow[t]{2}{*}{92.0} & \multirow[t]{2}{*}{ Hudson et al. (1984) } \\
\hline & Duckling & 112 & - & & \\
\hline
\end{tabular}

receiving the dose over 1 and $8 \mathrm{~h}$, respectively. Concentrations of CPY associated with no mortality were 1,000 and $3,200 \mathrm{mg}$ ai $\mathrm{kg}^{-1}$ diet for the two doses, respectively.

\subsection{Chronic Toxicity Studies}

No chronic toxicity studies on birds have been conducted for CPY since the review by Solomon et al. (2001). 


\subsection{Derivation of Effects Metrics}

The most realistic route of exposure for acute effects is the dietary exposure pathway. This pathway is preferred over oral gavage exposures because the latter are only relevant to situations where active ingredients are ingested rapidly in a single exposure or gorging situation (ECOFRAM 1999). Most, if not all, bird species found in agroecosystems are much more likely to continuously forage for food during the daylight hours (Best 1977; Fautin 1941; Kessel 1957; Kluijver 1950; Pinkowski 1978). Birds foraging near agricultural areas are likely to ingest a mixture of contaminated and non-contaminated food items throughout a day. Studies in which birds were exposed through the diet were available for only one of the focal species, the northern bobwhite (Beavers et al. 2007). However, when dietary exposures for northern bobwhite were converted to dose ingested, there was little evidence of a dose-response relationship. In that study, birds reduced their food intake rates at higher dietary concentrations. Because of this issue, the results of oral gavage studies were used to derive the acute effects metrics in this assessment. Using results of studies that dosed birds by a single oral dose via oral gavage is highly conservative because:

- Doses are administered as one large dose. In the field, most birds feed continuously throughout the day.

- Chlorpyrifos is rapidly biotransformed by birds to less-toxic metabolites. The half-life for metabolism and elimination of CPY is approximately 1-d (Bauriedel 1986). When feeding throughout the day, birds have the opportunity to detoxify and/or eliminate CPY before it accumulates to internal doses that result in lethality.

- Repeated exposure to CPY in the diet leads to avoidance (Bennett 1989; Fink 1978b; Kenaga et al. 1978; Stafford 2010). In the field, birds can switch to sources of food that are not contaminated with CPY or avoid feeding for short periods of time. There can be no avoidance with large single doses administered by intubation during a gavage study.

- In oral exposures, CPY is generally administered in corn oil or gelatin capsules. Such carriers have been shown to result in greater toxicity with other insecticides than occurred when the insecticides were adsorbed to food items consumed by birds in the field (Stafford 2007a, b). Use of corn oil or gelatin carriers maximizes the potential for a pesticide to be absorbed rapidly, more so than would occur in the field where the pesticide is bound to food items. When pesticides are mixed with food, or when consumed at a time when the gastro-intestinal (GI) tract has other food items present, they are absorbed less efficiently than when dosed as a bolus in pure form into an empty GI tract (Lehman-McKeeman 2008).

In this assessment, the preferred effects metrics were dose-response curves for the focal species of interest. However, acute dose-response curves could only be derived for two focal species, the northern bobwhite (C. virginianus) and the red-winged blackbird (A. phoenicieus). For other focal species, a Species Sensitivity Distribution (SSD) approach was used. With this approach, the 5th, 50th and 95th 
centiles from the fitted species sensitivity distribution were selected to represent the range of sensitivities of birds to CPY. A hypothetical dose-response curve was derived for each of these centile species by combining the estimated $\mathrm{LD}_{50}$ with a probit slope. Because of the toxicity mitigation problems noted above with dietary exposures, the acute effect metrics in this assessment were based upon the results of acceptable acute oral gavage toxicity studies (Table 4).

The following sections describe how the acute and chronic effects metrics were derived. A NOEL and LOEL were selected as the chronic effects metrics because the available chronic toxicity studies did not have a sufficient number of treatments (i.e., five or more) to enable derivation of dose-response curves. There were an insufficient number of tested species to permit development of a SSD for chronic toxicity data.

Acute dose-response relationships for focal species. The $\mathrm{LD}_{50}$, based on oral gavage, for the red-winged blackbird (A. phoeniceus) was $13.1 \mathrm{mg}^{\mathrm{ai} \mathrm{kg}} \mathrm{kg}^{-1} \mathrm{bwt}$ (Schafer and Brunton 1971), however, no probit slope was reported. To generate a dose-response curve for red-winged blackbird in this assessment, a geometric mean probit slope of 3.45 was calculated from the studies listed in Table 4. For northern bobwhite (C. virginianus), two $\mathrm{LD}_{50}$ s have been reported: 32 and $119 \mathrm{mg}$ ai $\mathrm{kg}^{-1}$ bwt (Hill and Camardese 1984; Kaczor and Miller 2000). The corresponding probit slopes from these studies were 4.6 and 3.88 , respectively. The resulting geometric mean $\mathrm{LD}_{50}$ and probit slope were $61.7 \mathrm{mg}$ ai $\mathrm{kg}^{-1}$ bwt and 4.22 . These values were used to generate the acute dose-response curve for northern bobwhite in this assessment.

SSD for acute toxicity of CPY to untested focal species. The data used in the derivation of the SSD for avian species are shown (Table 4). Multiple toxicity values were reported for several species. Variation in toxicity for a species could be the result of differences in experimental conditions, species strain, and/or test protocol. Using multiple toxicity results for the same species would disproportionately influence the SSD. In these situations, the geometric means were calculated (Table 4). Each bird species was then ranked according to sensitivity and its centralized position on the SSD determined using the Hazen plotting position equation (1) (Aldenberg et al. 2002):

$$
P P=\frac{i-0.5}{N}
$$

Where:

$P P$ is the plotting position;

$i$ is the species rank based on ascending $\mathrm{LD}_{50} \mathrm{~S}$; and

$N$ is the total number of species included in the SSD derivation.

The SSD was derived using SSD Master v2.0, which includes five models: normal, logistic, Weibull, extreme value (=Gompertz) and Gumbel (=Fisher-Tippett) (CCME 2013). All analyses were conducted in log space, except the Weibull model, which was conducted in arithmetic space because a log-Weibull model is the same as the Gumbel model. The log-normal model had the best fit of the five 
Fig. 6 Species sensitivity distribution for bird species exposed to chlorpyrifos via oral gavage exposure
Fig. 7 Hypothetical acute dose-response curves for sensitive, median and tolerant bird species
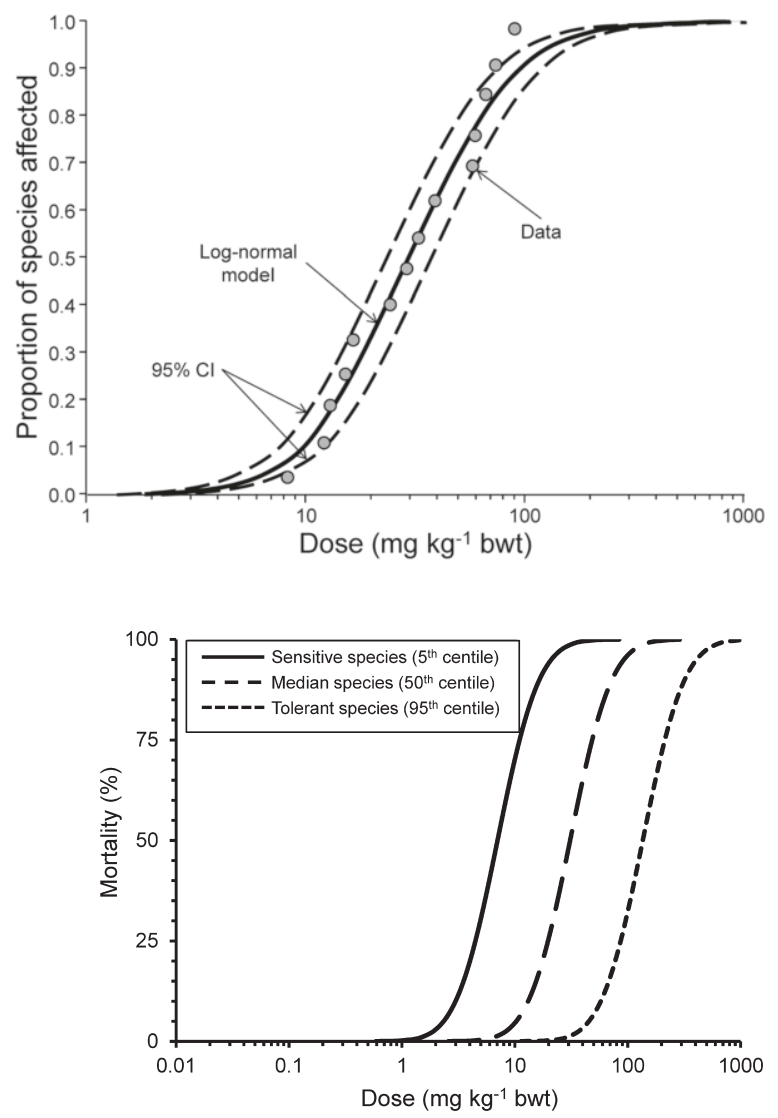

models tested (Anderson-Darling $\mathrm{A}^{2}=0.301, p>>0.1$ ). The model equation for the two-parameter log-normal cumulative distribution function (CDF) is shown below (2):

$$
f(x)=\frac{1}{2}\left(1+\operatorname{erf}\left(\frac{x-\mu}{\sigma \sqrt{2}}\right)\right)
$$

Where:

$x$ is the $\mathrm{LD}_{50}$ (log mg ai $\mathrm{kg}^{-1}$ bwt), and the functional response, $f(x)$, is the proportion of species affected. The location and scale parameters, $\mu$ and $\sigma$, are the mean and standard deviation of the dataset, respectively, and erf is the error function (i.e., the Gauss error function).

Graphical and statistical tests indicated that the homogeneity of variance and normality assumptions of the parametric regression analysis were met. The fitted model parameters were: $\mu=1.49$ and $\sigma=0.391$ (Fig. 6). The 5th, 50th and 95th centile $\mathrm{LD}_{50}$ s from the best-fit SSD are respectively 7.03, 30.9 and $136 \mathrm{mg}$ ai $\mathrm{kg}^{-1}$ bwt. These values were combined with the geometric mean probit slope of 3.45 (Table 4) to generate the hypothetical dose-response curves for avian species of high (5th centile), median (50th centile) and low (95th centile) sensitivity (Fig. 7). 


\subsection{Influence of Dietary Matrix on Acute Toxicity}

In a standard acute $\mathrm{LD}_{50}$ test, the test chemical is administered via gavage directly into the esophagus or crop of the bird, usually with a carrier such as corn oil, a solvent or water. Use of such carriers maximizes the potential for the chemical to be absorbed rapidly, more so than would occur in the field where the chemical is bound to food items. When pesticides are mixed with food, or consumed at a time when the gastrointestinal (GI) tract has other food items present, they are absorbed less efficiently than when dosed as a bolus in pure form into an empty GI tract (Lehman-McKeeman 2008).

To examine effects of excipient on toxicity, Hubbard and Beavers (2009) administered CPY to 19-wk old northern bobwhite (C. virginianus) using either corn oil or a feed slurry as the excipient. Groups of ten birds were randomly assigned to six treatment groups ranging from 0 (control) to $60 \mathrm{mg}$ ai $\mathrm{kg}^{-1} \mathrm{bwt}$. The dose was mixed with the chosen excipient and orally intubated into the crop or proventriculus of each bird. For corn oil as excipient, CPY was dispersed in corn oil, and for the feed slurry excipient, treated food was mixed with water at a ratio of 1:2.5. Birds were monitored for 14-d following dosing to evaluate effects on body weight, lethality, consumption of food, appearance, and abnormal behavior. No signs of toxicity were observed in control groups. When corn oil was used as the excipient, signs of toxicity

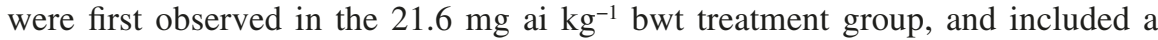
ruffled appearance and lethargy. Body weight of female birds exposed to $21.6 \mathrm{mg}$ ai $\mathrm{kg}^{-1}$ bwt decreased as did body weights in both sexes in the greater dose groups. Rate of consumption of food was reduced in males fed $36 \mathrm{mg}$ ai kg-1 bwt and in males and females fed $60 \mathrm{mg}$ ai $\mathrm{kg}^{-1}$ bwt. The NOEL was $13.0 \mathrm{mg}$ ai $\mathrm{kg}^{-1}$ bwt. Lethality only occurred in birds fed $60 \mathrm{mg}$ ai $\mathrm{kg}^{-1}$ bwt. Therefore, the $\mathrm{LD}_{50}$ was

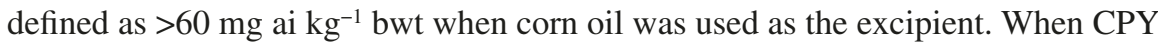
was diluted with feed slurry as the excipient, signs of toxicity were first observed in individuals exposed to $21.6 \mathrm{mg}$ ai $\mathrm{kg}^{-1}$ bwt. The signs of toxicity included a ruffled appearance and 1 lethality. Lethality skewed the observations for both change in body mass and rate of consumption of food. However, a lesser body mass was

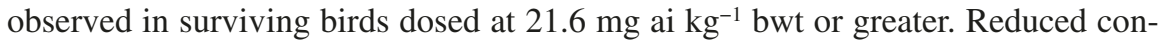
sumption of food was observed in female birds dosed at 21.6 and $36 \mathrm{mg} \mathrm{ai} \mathrm{kg}^{-1}$ bwt. The $\mathrm{LD}_{50}$ was $29.0 \mathrm{mg}$ ai $\mathrm{kg}^{-1}$ bwt and the NOEL was $13.0 \mathrm{mg}$ ai $\mathrm{kg}^{-1}$ bwt. In this study, the food-based slurry did not reduce toxicity compared to the corn oil excipient. Therefore, the acute effects metrics derived above were not adjusted to account for the dietary matrix consumed by birds in treated fields.

\subsection{Chronic NOEL and LOEL}

There is an insufficient number of studies to derive a chronic SSD for CPY. Further, there are no chronic studies with a sufficient number of treatments to enable derivation of a dose-response curve. Given the paucity of chronic toxicity studies for birds, 
we used a conservative approach and derived a NOEL and LOEL from the most sensitive species tested to date, viz., the mallard (A. platyrhynchos). In a 1-generation reproduction study (Fink 1978a), reduced reproductive success was observed at a concentration of $125 \mathrm{mg}$ ai $\mathrm{kg}^{-1}$ diet but no adverse effects were observed at a concentration of $25 \mathrm{mg}$ ai $\mathrm{kg}^{-1}$ diet. The primary response observed when birds were exposed to $125 \mathrm{mg}$ ai $\mathrm{kg}^{-1}$ diet was fewer eggs laid per hen. Therefore, rate of intake of food and body mass during the egg-laying phase of the study (i.e., the final 8-wk) were used as the measurement endpoints upon which to base the dietary NOEL and LOEL. Mean rates of intake of food at doses equivalent to the NOEC and LOEC were 0.134 and $0.140 \mathrm{~kg}$ diet bird ${ }^{-1} \mathrm{~d}^{-1}$, respectively. The corresponding average body masses were 1.12 and $0.934 \mathrm{~kg}$ bwt, respectively. The resulting dose-based NOEL and LOEL are 2.99 and $18.7 \mathrm{mg}$ ai $\mathrm{kg}^{-1}$ bwt d $\mathrm{d}^{-1}$, respectively. The NOEL and LOEL were used as thresholds for chronic effects in this refined assessment of risk.

\section{Risk Characterization for Flowable Chlorpyrifos}

For each acute exposure scenario, the fate of each bird was determined by converting estimated maximum retained dose to a standard normal $\mathrm{Z}$ score from the appropriate dose-response curve and comparing that value to a randomly drawn value from a uniform distribution with a range of 0-1 (see Sect. 3.2). This process was repeated for 20 individuals of each species on each of 1,000 fields. Results were then expressed as a risk curve indicating the percentage of fields that had $5 \%$ mortality ( $1 / 20$ birds died), $10 \%$ mortality (2/20 birds died), $15 \%$ mortality $(3 / 20$ birds died), etc. The Ecological Committee on FIFRA Risk Assessment Methods (ECOFRAM 1999) referred to such plots as "joint probability curves" while others refer to these plots as "risk curves" (e.g., Giddings et al. 2005; Moore et al. 2010a, b). For chronic exposure scenarios, risk was characterized by determining the probabilities that exposure exceeded the NOEL and LOEL for the most sensitive species tested.

The dose-response curve used to estimate acute risk depended on the focal species. If a dose-response curve was available for the focal species of interest, that curve was used (i.e., northern bobwhite (C. virginianus), red-winged blackbird (A. phoeniceus)). In the absence of species-specific dose-response curves, acute dose-response curves were generated for three hypothetical species representing a range of sensitivities (Fig. 7).

\subsection{Modeled Acute Risks from Flowable CPY}

The modeling for flowable CPY indicated that, with one exception, all bird species were at low or de minimis risk if they had median or lesser sensitivity to flowable CPY applied to alfalfa, almond, apple/cherry, broccoli, corn, grape, grapefruit, orange, pecan, soybean or sweet corn at the maximum application rates and minimum 
intervals specified on the label (Table 5). Assuming high sensitivity (5th centile on the species sensitivity distribution) to flowable CPY, or using actual doseresponse relationships indicated that several species, particularly those that forage extensively in crop fields such as the horned lark (Eremophila alpestris), blue grosbeak (Passerina caerulea), and red-winged blackbird (A. phoeniceus) are at intermediate or high risk in some crops (e.g., grape, grapefruit, orange) if treated at the maximum application rates and minimum treatment intervals.

\subsection{Modeled Chronic Risks from Flowable CPY}

For all patterns of use, the probability of birds having a total daily intake exceeding the LOEL was $<2 \%$ (Table 6). For most patterns of use and bird species, the probability of exceeding the NOEL was also small $(<5 \%)$. However, several species and crop combinations (e.g., vesper sparrow (Pooecetes gramineus) in alfalfa, red-winged blackbird (A. phoeniceus) in orange) had probabilities of exceeding the NOEL of approximately $20 \%$. The latter scenarios generally involved bird species that forage frequently in treated fields and crops with high maximum application rates (orange) or number of applications (alfalfa). In general, CPY poses little risk to birds from chronic exposure.

\subsection{Results of Field Studies for Flowable CPY}

Corn. Studies were performed with Lorsban $4 \mathrm{E}$ (a flowable formulation) on corn fields in Warren and Madison counties, Iowa (Frey et al. 1994). Lorsban 4E was applied at $3.36 \mathrm{~kg} \mathrm{ha}^{-1}\left(3 \mathrm{lb}\right.$ ai $\left.\mathrm{A}^{-1}\right)$ during the pre-plant stage (ground broadcast), and at $1.7 \mathrm{~kg} \mathrm{ha}^{-1}\left(1.5 \mathrm{lb}\right.$ ai A$\left.{ }^{-1}\right)$ during the emergence (ground broadcast), whorl (aerial broadcast) and tassel (aerial broadcast) stages. Monitoring of fields for birds exhibiting signs of toxicity was done prior to each application and for 13-d following each application, including abundance determinations, carcass search efficiency evaluations, and residue analyses.

Following pre-plant and at-plant applications, collection of moribund birds did not reveal differences among the treated and control fields and invertebrates collected during this period did not have detectable CPY residues. Applications during the emergence test period caused no statistically significant differences in the numbers of dead birds found, but the casualty rate was higher in treated fields ( 0.14 casualties per search) than in control fields (0.04 casualties per search).

During the whorl test period, bird censuses and mortality rates were similar in control and treated fields. Following tassel stage application, bird censuses did not reveal any differences in mortality among fields. Two robins (Turdus migratorius) collected from the fields treated with flowable CPY exhibited signs of toxicity consistent with inhibition of cholinesterase activity. One bird died, while the other bird recovered and was released. 


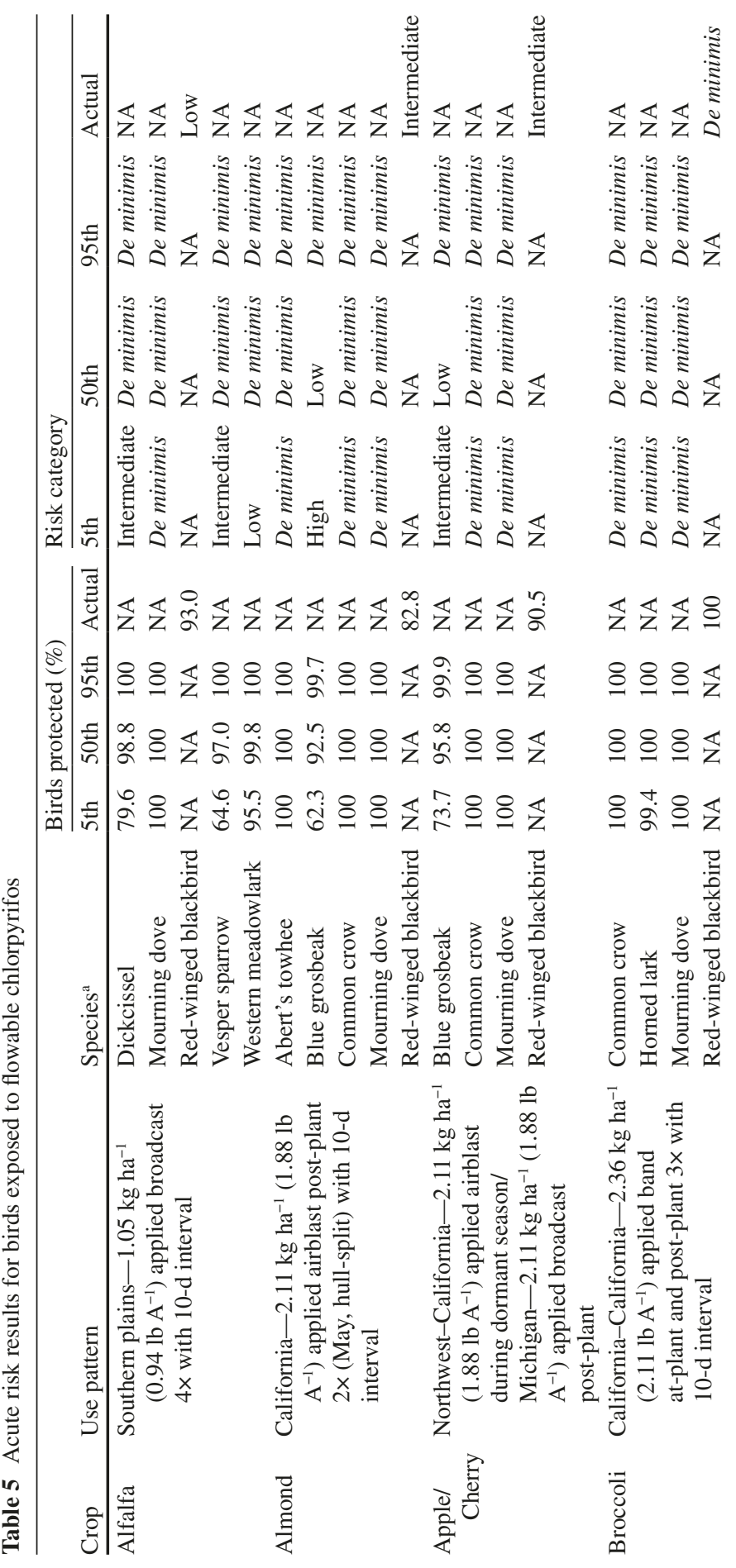




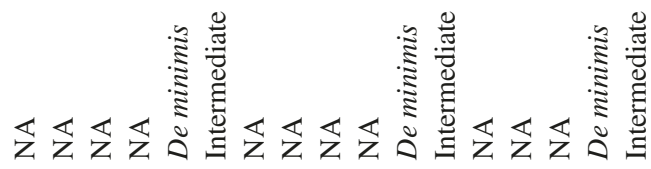

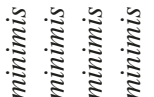

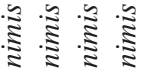

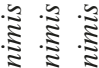

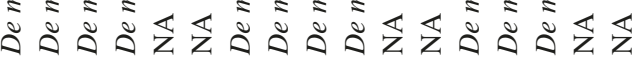


ปัป



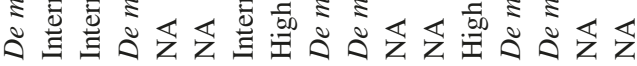

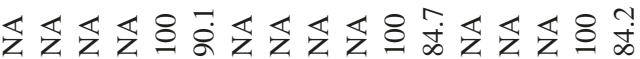

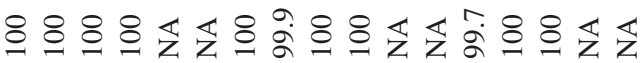

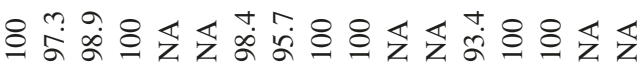

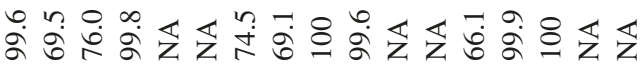

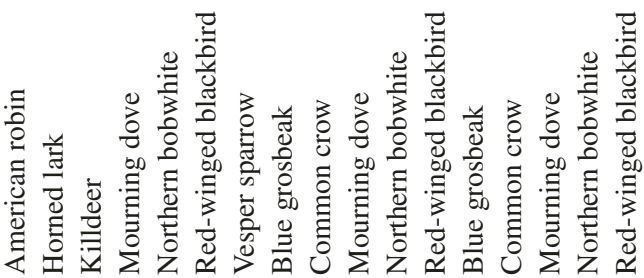
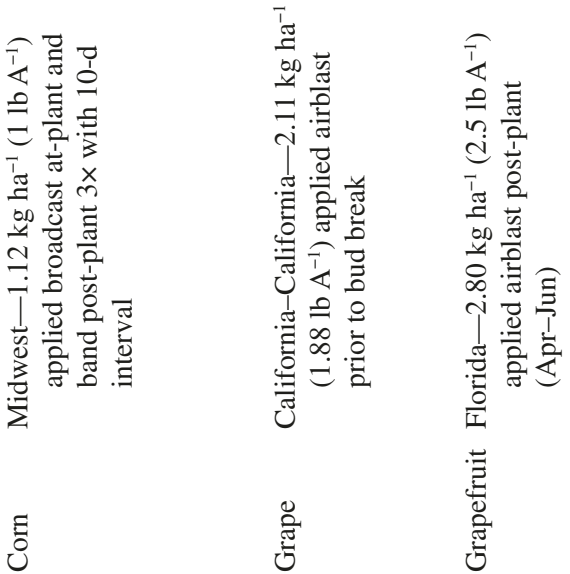


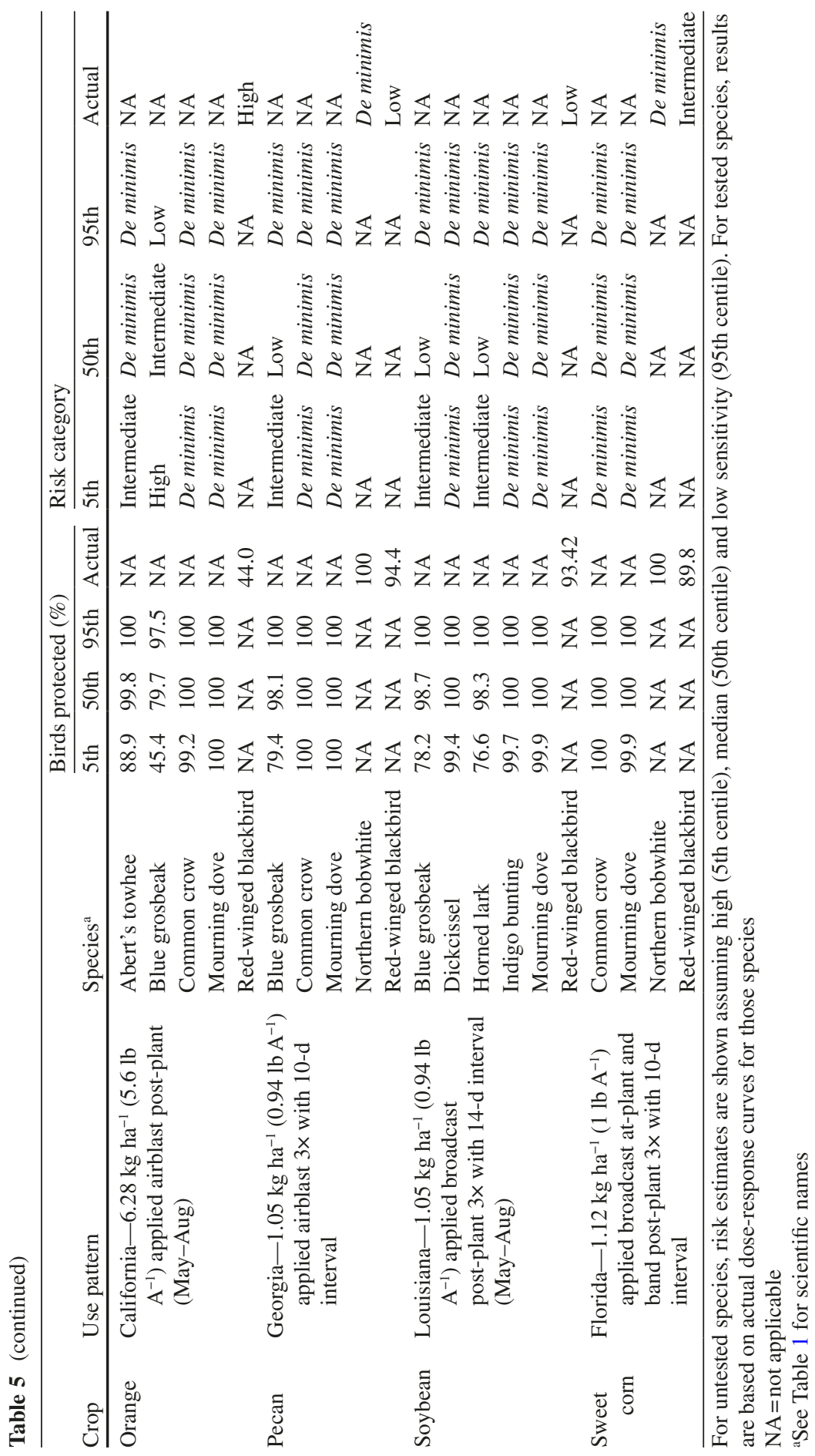


Table 6 Chronic risk results for birds exposed to flowable chlorpyrifos

\begin{tabular}{|c|c|c|c|c|}
\hline \multirow[b]{2}{*}{ Crop } & \multirow[b]{2}{*}{ Use pattern } & \multirow[b]{2}{*}{ Species $^{\mathrm{a}}$} & \multicolumn{2}{|c|}{$\begin{array}{l}\text { Exceedence } \\
\text { probability }(\%)\end{array}$} \\
\hline & & & NOEL & LOEL \\
\hline \multirow[t]{5}{*}{ Alfalfa } & \multirow{5}{*}{$\begin{array}{l}\text { Southern plains }-1.05 \mathrm{~kg} \mathrm{ha}^{-1}(0.94 \mathrm{lb} \\
\left.\mathrm{A}^{-1}\right) \text { applied broadcast } 4 \times \text { with } 10-\mathrm{d} \\
\text { interval }\end{array}$} & Dickcissel & 0.29 & 0 \\
\hline & & Mourning dove & 0 & 0 \\
\hline & & Red-winged blackbird & 0.61 & 0 \\
\hline & & Vesper sparrow & 18.6 & 0 \\
\hline & & Western meadowlark & 0.35 & 0 \\
\hline \multirow[t]{5}{*}{ Almond } & \multirow{5}{*}{$\begin{array}{l}\text { California-2.11 } \mathrm{kg} \mathrm{ha}^{-1}\left(1.88 \mathrm{lb} \mathrm{A}^{-1}\right) \\
\text { applied airblast post-plant } 2 \times(\mathrm{May}, \\
\text { hull-split) with } 10-\mathrm{d} \text { interval }\end{array}$} & Abert's towhee & 0.01 & 0 \\
\hline & & Blue grosbeak & 18.7 & 0.09 \\
\hline & & Common crow & 0 & 0 \\
\hline & & Mourning dove & 0 & 0 \\
\hline & & Red-winged blackbird & 9.71 & 0.01 \\
\hline \multirow{4}{*}{$\begin{array}{l}\text { Apple/ } \\
\text { Cherry }\end{array}$} & \multirow{4}{*}{$\begin{array}{l}\text { Northwest-2.11 kg ha } \mathrm{k}^{-1}\left(1.88 \mathrm{lb} \mathrm{A}^{-1}\right) \\
\text { applied airblast during dormant season/ } \\
\text { Michigan-2.07 } \mathrm{kg} \mathrm{ha}^{-1}\left(1.88 \mathrm{lb} \mathrm{A}^{-1}\right) \\
\text { applied broadcast post-plant }\end{array}$} & Blue grosbeak & 7.94 & 0.01 \\
\hline & & Common crow & 0 & 0 \\
\hline & & Mourning dove & 0 & 0 \\
\hline & & Red-winged blackbird & 1.99 & 0 \\
\hline \multirow[t]{4}{*}{ Broccoli } & \multirow{4}{*}{$\begin{array}{l}\text { California- }-2.36 \mathrm{~kg} \mathrm{ha}^{-1}\left(2.11 \mathrm{lb} \mathrm{A}^{-1}\right) \\
\text { applied band at-plant and post-plant } 3 \times \\
\text { with } 10-\mathrm{d} \text { interval }\end{array}$} & Common crow & 2.15 & 0 \\
\hline & & Horned lark & 1.27 & 0 \\
\hline & & Mourning dove & 0.02 & 0 \\
\hline & & Red-winged blackbird & 0.32 & 0 \\
\hline \multirow[t]{7}{*}{ Corn } & \multirow{7}{*}{$\begin{array}{l}\text { Midwest- } 1.12 \mathrm{~kg} \mathrm{ha}^{-1}\left(1 \mathrm{lb} \mathrm{A}^{-1}\right) \text { applied } \\
\text { broadcast at-plant and band post-plant } \\
3 \times \text { with } 10-\mathrm{d} \text { interval }\end{array}$} & American robin & 1.63 & 0 \\
\hline & & Horned lark & 1.89 & 0 \\
\hline & & Killdeer & 0.12 & 0 \\
\hline & & Mourning dove & 0 & 0 \\
\hline & & Northern bobwhite & 0 & 0 \\
\hline & & Red-winged blackbird & 0.25 & 0 \\
\hline & & Vesper sparrow & 0.43 & 0 \\
\hline \multirow[t]{5}{*}{ Grape } & \multirow{5}{*}{$\begin{array}{r}\text { California-2.11 } \mathrm{kg} \mathrm{ha}^{-1}\left(1.88 \mathrm{lb} \mathrm{A}^{-1}\right) \\
\text { applied airblast prior to bud break }\end{array}$} & Blue grosbeak & 4.86 & 0 \\
\hline & & Common crow & 0.39 & 0 \\
\hline & & Mourning dove & 0 & 0 \\
\hline & & Northern bobwhite & 0 & 0 \\
\hline & & Red-winged blackbird & 3.53 & 0 \\
\hline \multirow[t]{5}{*}{ Grapefruit } & \multirow{5}{*}{$\begin{array}{l}\text { Florida-2.80 kg ha-1 }\left(2.5 \mathrm{lb} \mathrm{A}^{-1}\right) \text { applied } \\
\text { airblast post-plant (Apr-Jun) }\end{array}$} & Blue grosbeak & 10.3 & 0.11 \\
\hline & & Common crow & 0 & 0 \\
\hline & & Mourning dove & 0 & 0 \\
\hline & & Northern bobwhite & 0 & 0 \\
\hline & & Red-winged blackbird & 5.49 & 0 \\
\hline \multirow[t]{5}{*}{ Orange } & \multirow{5}{*}{$\begin{array}{l}\text { California- }-6.27 \mathrm{~kg} \mathrm{ha}^{-1}\left(5.6 \mathrm{lb} \mathrm{A}^{-1}\right) \\
\text { applied airblast post-plant (May-Aug) }\end{array}$} & Abert's towhee & 0.08 & 0 \\
\hline & & Blue grosbeak & 28.1 & 1.12 \\
\hline & & Common crow & 0 & 0 \\
\hline & & Mourning dove & 0 & 0 \\
\hline & & Red-winged blackbird & 21.0 & 0.8 \\
\hline \multirow[t]{5}{*}{ Pecan } & \multirow{5}{*}{$\begin{array}{l}\text { Georgia- } 1.05 \mathrm{~kg} \mathrm{ha}^{-1}\left(0.94 \mathrm{lb} \mathrm{A}^{-1}\right) \\
\text { applied airblast } 3 \times \text { with } 10-\mathrm{d} \text { interval }\end{array}$} & Blue grosbeak & 11.8 & 0.02 \\
\hline & & Common crow & 0 & 0 \\
\hline & & Mourning dove & 0 & 0 \\
\hline & & Northern bobwhite & 0 & 0 \\
\hline & & Red-winged blackbird & 4.58 & 0 \\
\hline
\end{tabular}


Table 6 (continued)

\begin{tabular}{|c|c|c|c|c|}
\hline \multirow[b]{2}{*}{ Crop } & \multirow[b]{2}{*}{ Use pattern } & \multirow[b]{2}{*}{ Species $^{\mathrm{a}}$} & \multicolumn{2}{|c|}{$\begin{array}{l}\text { Exceedence } \\
\text { probability }(\%)\end{array}$} \\
\hline & & & NOEL & LOEL \\
\hline \multirow[t]{6}{*}{ Soybean } & \multirow{6}{*}{$\begin{array}{l}\text { Louisiana-1.05 } \mathrm{kg} \mathrm{ha}^{-1}\left(0.94 \mathrm{lb} \mathrm{A}^{-1}\right) \\
\text { applied broadcast post-plant } 3 \times \text { with } \\
\text { 14-d interval (May-Aug) }\end{array}$} & Blue grosbeak & 0.07 & 0 \\
\hline & & Dickcissel & 0.07 & 0 \\
\hline & & Horned lark & 4.77 & 0 \\
\hline & & Indigo bunting & 5.74 & 0 \\
\hline & & Mourning dove & 0 & 0 \\
\hline & & Red-winged blackbird & 0.22 & 0 \\
\hline \multirow{4}{*}{$\begin{array}{l}\text { Sweet } \\
\text { corn }\end{array}$} & \multirow{4}{*}{$\begin{array}{l}\text { Florida-1.12 } \mathrm{kg} \mathrm{ha}^{-1}\left(1 \mathrm{lb} \mathrm{A}^{-1}\right) \text { applied } \\
\text { broadcast at-plant and band post-plant } \\
3 \times \text { with } 10 \text {-d interval }\end{array}$} & Common crow & 0.37 & 0 \\
\hline & & Mourning dove & 0 & 0 \\
\hline & & Northern bobwhite & 0 & 0 \\
\hline & & Red-winged blackbird & 0.66 & 0 \\
\hline
\end{tabular}

$\mathrm{NA}=$ not applicable



Overall, flowable CPY had minimal effects on birds in treated corn fields (1994). This result occurred in spite of far greater rates of application being used in the field study $\left(3.36 \mathrm{~kg} \mathrm{ha}^{-1}\left(3 \mathrm{lb}\right.\right.$ ai $\left.\mathrm{A}^{-1}\right)$ during the pre-plant stage, $1.7 \mathrm{~kg} \mathrm{ha}^{-1}\left(1.5 \mathrm{lb}\right.$ ai A $\left.\mathrm{A}^{-1}\right)$ applied broadcast postplant $3 \times$ ) than currently allowed on the Lorsban Advanced label for corn $\left(1.12 \mathrm{~kg} \mathrm{ha}^{-1}\left(1 \mathrm{lb}\right.\right.$ ai $\left.\mathrm{A}^{-1}\right)$ applied broadcast at-plant and band post-plant $3 \times$ with 10-d interval) The results of the field study suggest that the LiquidPARAM modeling exercise overestimated risks to birds, particularly for the horned lark (E. alpestris) and killdeer (Charadrius vociferous) (assuming high sensitivity) and the redwinged blackbird (A. phoeniceus) (Table 5).

Brassica. Three cabbage fields in central Poland, were chosen to study the effects of CPY application on associated bird communities (Moosmayer and Wilkens 2008). Dursban $^{\circledR} 480$ EC, a flowable formulation of CPY, was applied twice at a rate of $0.95 \mathrm{~kg} \mathrm{ha}^{-1}\left(0.85 \mathrm{lb} \mathrm{A}^{-1}\right)$ with an application interval of 14-d. Visual searches for carcasses, monitoring of nests and radio-tracking were used to estimate adverse effects to wildlife. No signs of toxicity were observed during the visual searches or monitoring of nests and no carcasses were recovered from the treated fields. Fifty-three birds were caught, radio-tagged, and tracked over the treatment period. None of the radio-tagged birds experienced adverse effects related to application of CPY.

Although there were no significant effects to birds in the brassica field study, it was not possible to determine whether predictions of LiquidPARAM of little or no risk to birds (Table 5) were reasonable because the application rates in the field study were less than half the rate used in the modeling exercise.

Citrus. Effects of Lorsban 4E applied in California citrus groves to birds were determined by Gallagher et al. (1994). Two application scenarios were included in the study: (1) $1.65 \mathrm{~kg} \mathrm{ha}^{-1}\left(1.5 \mathrm{lb}\right.$ ai $\left.\mathrm{A}^{-1}\right)$ Lorsban 4E applied post bloom and $6.62 \mathrm{~kg} \mathrm{ha}^{-1}$ (6 lb ai $\mathrm{A}^{-1}$ ) after petal-fall and (2) $3.86 \mathrm{~kg} \mathrm{ha}^{-1}\left(3.5 \mathrm{lb}\right.$ ai $\left.\mathrm{A}^{-1}\right)$ applied post bloom and $4.4 \mathrm{~kg} \mathrm{ha}^{-1}\left(4 \mathrm{lb}\right.$ ai $\left.\mathrm{A}^{-1}\right)$ post petal fall. The post-bloom applications were made 
in early spring and the post petal fall applications were made in late spring. The first and second applications were 30-35-d apart.

Casualties among birds residing on fields following post-bloom application (1.65 $\mathrm{kg} \mathrm{ha}^{-1}\left(1.5 \mathrm{lb}\right.$ ai $\left.\mathrm{A}^{-1}\right)$ ) from the first application scenario could not be linked to CPY, because no detectable residues of the parent compound were found in the dead birds. There were no bird casualties from the second post-bloom application scenario.

Following applications after petal fall, one dead northern mockingbird (Mimus polyglottos) was found on the fields from the first application scenario $\left(6.62 \mathrm{~kg} \mathrm{ha}^{-1}\left(6 \mathrm{lb}\right.\right.$ ai $\left.\left.\mathrm{A}^{-1}\right)\right)$. The dead bird had measurable residues of CPY on its feathers $\left(5.39 \mathrm{mg}\right.$ ai $\left.\mathrm{kg}^{-1} \mathrm{bwt}\right)$. In the second application scenario $\left(4.4 \mathrm{~kg} \mathrm{ha}^{-1}\right.$ $\left(4 \mathrm{lb}\right.$ ai $\left.\mathrm{A}^{-1}\right)$ ), concentrations of $3.67 \mathrm{mg}$ ai $\mathrm{kg}^{-1}$ bwt CPY were measured in a dead passerine nestling. It is not known if the deaths were treatment related.

In a similar study, three citrus orchards in Spain were spayed twice at a rate of $2.32 \mathrm{~kg} \mathrm{ha}^{-1}\left(2.1 \mathrm{lb}\right.$ ai A $\left.{ }^{-1}\right)$ of Dursban ${ }^{\circledR} 75 \mathrm{WG}$ with a 14-d re-treatment interval (Selbach and Wilkens 2008a). Birds were captured before each spray application, radio-tagged and released. Birds were then tracked for 3-d before and 7-d after each application. Monitoring of the activities of radio-tagged birds, monitoring of nests, searches for carcasses, and surveys of masses of arthropod biomass were also used to quantify possible adverse effects to birds from application of Dursban. Of the 38 birds tracked during the study, 6 were continuously tracked through both application periods. The tracked birds spent approximately one third of their time in the treated orchards before and after application. Of the 3,751 sightings of birds made during the observation periods, no birds showed signs of toxicity. Three bird carcasses were found. Chlorpyrifos residues of $14 \mathrm{mg}^{\mathrm{ai} \mathrm{kg}} \mathrm{kg}^{-1}$ bwt were found in the skin and feather matrix of a blackbird and $1.2 \mathrm{mg}$ ai $\mathrm{kg}^{-1}$ bwt was detected in the core body matrix. A blackbird (unknown species name) wing was found that contained $6.5 \mathrm{mg}$ CPY ai kg-1 bwt in the skin and feathers. Lastly, a dead house martin

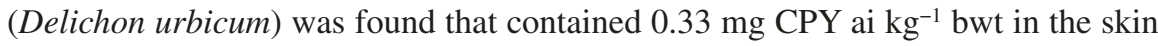
and feathers. No CPY was detected in the core body matrix of the house martin or wing of the blackbird. No inhibition of AChE activity in the brain of the house martin was observed. The authors determined that none of the casualties resulted from the CPY application.

Another study was conducted in citrus orchards in Spain to determine the effects of CPY on bird communities and reproductive performance (Dittrich and Staedtler 2010). Observations of communities of birds were made at the end of the main breeding season (July 6 to August 31, 2010) on ten citrus orchards that routinely use CPY to control arthropods (application period: April 1 to June 30, 2010). No additional details on use patterns and application rates were provided. A large diversity and number of birds was observed in the study area. No losses of nests could be attributed to CPY. The bird species most frequently observed were serin, green finch (Carduelis chloris), and house sparrow (Passer domesticus), while the juveniles most frequently observed were barn swallow (Hirundo rustica), nightingale (Luscinia megarhynchos), and Sardinian warbler (Sylvia melanocephala). Sampling of arthropods following application indicated an abundance of avian food items. 
Overall, the bird community residing within the treated citrus fields was considered to be highly viable.

The results of the 3 field studies in citrus orchards indicated that flowable CPY applied at rates comparable to the maximum rate allowed by the label for Lorsban Advanced (i.e., $6.17 \mathrm{~kg} \mathrm{ha}^{-1}\left(5.6 \mathrm{lb}\right.$ ai $\mathrm{A}^{-1}$ ) for use in oranges) had no significant adverse effects on birds. As with the corn field studies, the citrus field studies indicate that LiquidPARAM may be overestimating avian risks in citrus orchards (Table 5).

Apple. Dursban $75 \mathrm{WG}$ was applied to three apple orchards at a rate of $0.95 \mathrm{~kg} \mathrm{ha}^{-1}$ (0.86 $\mathrm{lb}_{\text {ai }} \mathrm{A}^{-1}$ ) (Wilkens et al. 2008). Three applications were made to the first orchard with the first and second applications being 14-d apart and the second and third being 28-d apart. Two applications were made to the other two orchards, 14-d apart. Telemetric surveys, visual bird observations, carcass searches, and nest observations were used to quantify the effects of CPY. Radio-tagged birds were tracked for 3-d prior to applications and for 7-d following applications. Birds spent approximately half of their time in the study plots. No tracked birds exhibited signs of toxicity. A total of 3,616 bird observations were made during the study period and no birds exhibited any behavioral abnormalities or signs of toxicity. Only one dead bird was found during the study period. The authors concluded that this death resulted from a collision with a power transmission line. However, the applications did reduce populations of foliage-dwelling pest and non-target arthropods by approximately $87 \%$. There were no significant effects to birds in the apple field study, because the application rates in the field study were approximately half that used in the modeling exercise. Therefore, it cannot be determined whether LiquidPARAM overestimated risks to the blue grosbeak (Table 5) or not.

Grape. Dursban $480 \mathrm{EC}$ was applied twice at a rate of $0.36 \mathrm{~kg} \mathrm{ha}^{-1}\left(0.32 \mathrm{lb}\right.$ ai A $\left.{ }^{-1}\right)$ with a 15-d interval to a vineyard in Puy du Maupas, near Puymeras, Vaucluse, Southern France (Brown et al. 2007). The vineyard consisted of eight adjacent fields, with grass growing between the planted rows. The property also contained scrub, woodland, garden, and grassy areas. The area was searched for carcasses of birds prior to each application of CPY and 1, 3 and 7-d following each application. Three to 4-d prior to each application, mist nests were placed in the vineyard and along the boundaries. Collected birds were banded, sexed, measured, and radiotagged. Tagged birds were tracked for several days prior to treatment and for up to 10- $\mathrm{d}$ following treatment. The locations of birds were used to estimate the proportion of time spent on the treated fields and to determine if the birds were alive.

Monitoring of the radio-tagged birds indicated that birds spent a maximum of $20 \%$ of their time on the treated fields. Only Cirl buntings (Emberiza cirlus), black redstarts (Phoenicurus ochruros), stonechats (Saxicola sp.), and jays (unknown species name) spent more than $5 \%$ of their time there. Birds on the treated crop for the greatest proportion of time were alive at the end of the tracking period. Only one radio-tagged bird was found dead during the monitoring period and, because only a leg was found, it is unlikely that mortality was the result of CPY. Untagged birds found dead during the study had residues of CPY on skin and feather residue levels that were consistent with contact with the treated crop $(0.27-1.3 \mathrm{mg}$ ai kg-1 bwt). Analysis of AChE activity in the brain of a dead robin (Erithacus rubecula) showed 
no decrease in activity, indicating that mortality was not likely the result of exposure to CPY. There were no indications of short-term negative impacts from CPY on birds in the vineyard during the study. There were no significant effects to birds in the grape field study, however the application rate in this field study was well below that used in the modeling exercise. Therefore, it was not possible to determine whether LiquidPARAM overestimated risks to the blue grosbeak (P. caerulea) (Table 5).

Telemetry-based field studies. Brassica, pome fruit and citrus crops were treated with CPY to determine potential effects on wild birds (Wolf et al. 2010). Brassica fields were located near Sochaczew, Poland, pome fields near Belfiore, northern Italy, and citrus groves in Valencia, Spain. Four or five sites were used for each crop type and fields averaged 4 ha (9.9 A) in size. Chlorpyrifos was applied to brassicas using a tractor-mounted boom sprayer at a rate of $0.95 \mathrm{~kg} \mathrm{ha}^{-1}\left(0.86 \mathrm{lb}\right.$ ai A $\left.{ }^{-1}\right)$. Three brassica sites received two applications of Dursban 480 EC and two other sites received an application of a formulation not relevant to this assessment (Pyrinex $^{\circledR} 25 \mathrm{CS}$, a microencapsulated formulation). Chlorpyrifos was applied to pome and citrus fruit crops using a tractor-mounted broadcast air-assisted sprayer. Three citrus fields received two applications of Dursban $75 \mathrm{WG}$ at a rate of $2.32 \mathrm{~kg} \mathrm{ha}^{-1}\left(2.1 \mathrm{lb}\right.$ ai $\left.\mathrm{A}^{-1}\right)$, and the remaining field received two applications of Pyrinex $25 \mathrm{CS}$. One field of pome fruit received applications of Pyrinex $25 \mathrm{CS}$ and one pome fruit field received three applications of $0.95 \mathrm{~kg} \mathrm{ha}^{-1}\left(0.86 \mathrm{lb}\right.$ ai A $\left.\mathrm{A}^{-1}\right)$ Dursban $75 \mathrm{WG}$, whereas the other two plots received two applications of $0.95 \mathrm{~kg} \mathrm{ha}^{-1}\left(0.86 \mathrm{lb}\right.$ ai $\left.\mathrm{A}^{-1}\right)$ Dursban $75 \mathrm{WG}$. All bird species regularly foraging in the crops were monitored during the study.

Birds were trapped and radio-tagged before each application and tracked for 7-d following each application. Those tagged for earlier applications were monitored during subsequent applications if the radio-tags were still functional. Of the 242 radio-tagged birds, 194 were tracked for the full 7-d period following application. No signs of toxicity or lethality were observed. Un-tagged birds were also observed during the study period. No signs of toxicity were detected. Ten bird carcasses were found during the study, six of which had detectable levels of CPY. Detectable concentrations of CPY on skin and feathers ranged from 0.3 to $14.0 \mathrm{mg}$ ai kg-1 bwt. CPY was only detected in the bodies of two birds (1.2 and $0.3 \mathrm{mg} \mathrm{ai} \mathrm{kg}^{-1} \mathrm{bwt}$ ). Similarly, core body concentrations of CPY were only detected in two birds at levels of 0.1 and $1.2 \mathrm{mg}$ ai $\mathrm{kg}^{-1}$ bwt.

Rates of application used in the pome (e.g., apple) and brassica plots were less than the maximum rates listed on the Lorsban Advanced label for those crops. The rate of application used in the citrus plots $\left(2.32 \mathrm{~kg} \mathrm{ha}^{-1}\left(2.1 \mathrm{lb}^{\mathrm{ai} \mathrm{A}} \mathrm{A}^{-1}\right)\right)$ was similar to the maximum rate of application for grapefruit on the Lorsban Advanced label (i.e., $2.76 \mathrm{~kg} \mathrm{ha}^{-1}\left(2.5 \mathrm{lb}\right.$ ai $\left.\mathrm{A}^{-1}\right)$ ). LiquidPARAM predicted approximately $34 \%$ mortality to blue grosbeaks ( $P$. caerulea) in grapefruit treated at the maximum rate of application, assuming that this species was highly sensitive (Table 5). All other bird species were predicted to experience little to no mortality. The results for citrus groves indicate that LiquidPARAM might be over-estimating risk to blue grosbeaks (Wolf et al. 2010). 
Fig. 8 Percentage of bird species affected versus percent mortality for flowable chlorpyrifos applied broadcast at-plant and band post-plant at a rate of $1.12 \mathrm{~kg} \mathrm{ha}^{-1}\left(1 \mathrm{lb}\right.$ ai $\left.\mathrm{A}^{-1}\right) 3 \times$ with a 10 -d interval to corn fields

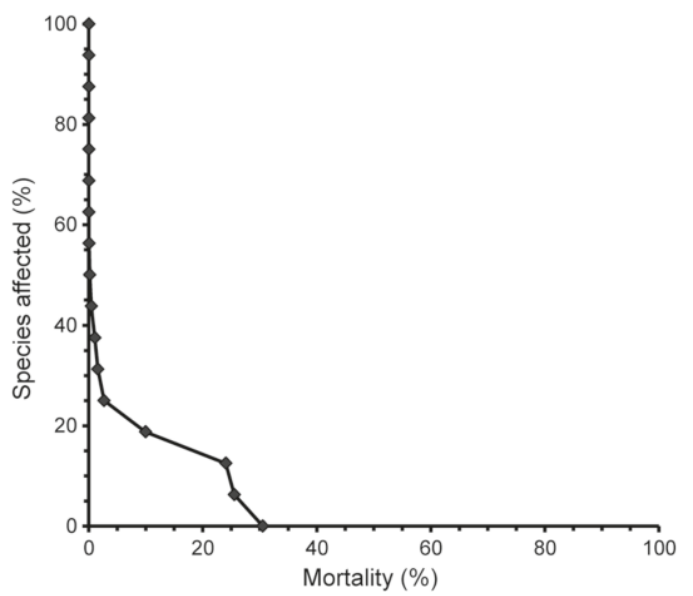

\subsection{Discussion of Avian Risks for Flowable CPY}

There are a number of bird species that frequent agroecosystems besides those included as focal species in this assessment (see Best and Murray 2003). The USEPA (USEPA 2005) used estimates of mortality for the combination of focal species and bird sensitivities in each modeled exposure scenario to approximate the cumulative distribution of outcomes for the complex of species using treated fields. The approach assumes that the focal species included in the modeling exercise are representative of the birds and their exposures occurring in the fields (USEPA 2005). This assumption is supported by the selection of focal species known to occur on the treated crops by actual survey (e.g., Best and Murray 2003). According to the USEPA (2005), the outcomes of the three modeled sensitivity assumptions (low, median and high sensitivity) "can be viewed as a stratified sample from the population which estimates the limits and mid points of the cumulative risk distribution and therefore provides a reasonable approximation of the distribution."

The resulting cumulative distribution of acute risk for banded application on corn at the maximum application rate of $1.12 \mathrm{~kg} \mathrm{ha}^{-1}\left(1 \mathrm{lb}^{\mathrm{bi} \mathrm{A}} \mathrm{A}^{-1}\right)$ is shown in Fig. 8 . Results of simulations using LiquidPARAM indicate that several species of birds, if highly sensitive, would experience up to approximately $30 \%$ mortality. Similar results were predicted for alfalfa, almond, apple/cherry, grape, grapefruit and soybean (Table 5). For orange, somewhat greater risk is expected in the bird community because this crop has the greatest application rate allowed on the Lorsban Advanced label (i.e., $6.27 \mathrm{~kg} \mathrm{ha}^{-1}$ (5.6 lb ai A ${ }^{-1}$ )) (Fig. 9).

Although the results of the LiquidPARAM modeling indicated some acute risk to the most sensitive species for several crops listed on the Lorsban Advanced label (Table 5), the evidence from field studies that used the corresponding application rates (i.e., corn, grapefruit, and orange) indicate that flowable CPY poses little risk to birds (Dittrich and Staedtler 2010; Frey et al. 1994; Gallagher et al. 1994; Selbach and Wilkens 2008b; Wolf et al. 2010). Thus, it would appear that LiquidPARAM 
Fig. 9 Percentage of bird species affected versus percent mortality for flowable chlorpyrifos applied airblast to orange orchards at a rate of $6.28 \mathrm{~kg} \mathrm{ha}^{-1}\left(5.6 \mathrm{lb} \mathrm{A}^{-1}\right)$

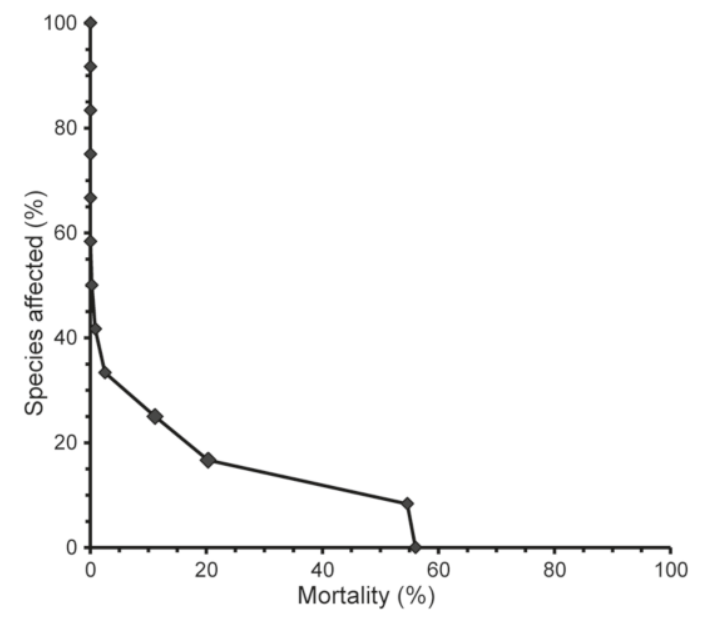

may be overestimating the risk CPY poses to birds, particularly in those crops with the highest application rates (i.e., grapefruit and orange). There are several potential reasons why LiquidPARAM may be overestimating acute risks of CPY to birds. For example, acute effects metrics were based on single-dose, oral gavage studies that likely overestimate the toxicity that birds would experience when consuming small amounts over the course of a day, as typically occurs in treated fields (see Sect. 5.3). In addition, the exposure model assumed that proportion time in treated fields equates to proportion diet obtained from treated fields. However, it may be that many bird species obtain a relatively higher proportion of their diet from higher quality edge habitats.

The results of field studies consistently demonstrated that flowable CPY has negligible effects on birds at rates well above the application rate of CPY predicted by Mineau (2002) (i.e., $0.19-0.26 \mathrm{~kg} \mathrm{ha}^{-1}\left(0.17-0.23 \mathrm{lb}\right.$ ai $\left.\mathrm{A}^{-1}\right)$ ) to have a $1 / 10$ probability of an avian kill.

\subsection{Strengths of the Refined Risk Assessment for Flowable CPY}

LiquidPARAM explicitly accounts for factors affecting exposure of birds to flowable CPY in the field. These factors include: application rates, number and types of applications, foraging patterns, preferred diets, CPY concentrations on dietary items over time and space, rates of metabolism, and avoidance behavior.

In several instances, LiquidPARAM refined the approach used by EPA's TIM (USEPA 2005). For proportion of time foraging in treated fields, TIM uses data that represent inter-field variability as intra-field variability. In estimating food intake rate, TIM uses distributions for several minor input variables (e.g., gross energy and assimilation efficiency of dietary items), but treats the input variable with the greatest uncertainty (i.e., free metabolic rate, the amount of calories consumed by free-living 


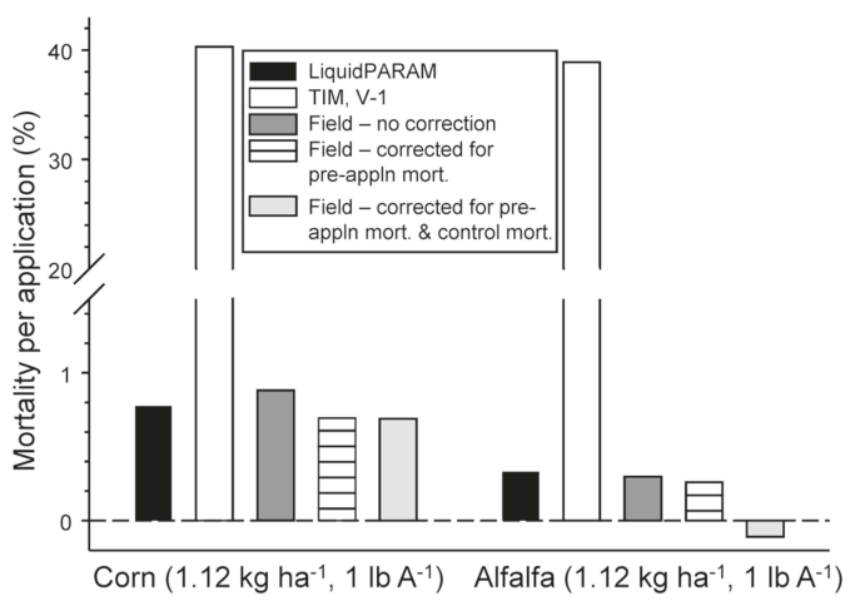

Fig. 10 Percent mortality per application of Furadan ${ }^{\circledR} 4 \mathrm{~F}$ in corn and alfalfa as estimated by LiquidPARAM, TIM (v1), and observed in field studies by Booth et al. (1989) and Jorgensen et al. (1989)

birds per time step) as a point estimate. Free metabolic rate is treated as a distribution in LiquidPARAM.

LiquidPARAM has several capabilities not available in TIM. These include: (1) The ability to model exposure scenarios involving multiple applications of pesticide taking place at a user-specified interval; (2) Addition of many new crops; (3) Addition of ten new focal bird species; and (4) The ability of users to select day length, time of application for first, second, and third applications, and length of time that dew is present on treated fields.

As described in SI Appendix 3, Sect. 1.4, sensitivity analysis and evaluation of model performance has been undertaken for LiquidPARAM. The sensitivity analysis was useful in determining which variables had an important influence on acute and chronic risk for bird species in high exposure scenarios (e.g., choice of drinking water scenario and chronic averaging period in the chronic modeling simulations) and in low exposure scenarios (varying any one factor had little effect on estimated acute or chronic risk to birds regardless of assumed sensitivity).

In addition to the sensitivity analysis, the model for LiquidPARAM has been evaluated. Field studies involving the application of flowable carbofuran, a carbamate pesticide that inhibits brain and plasma acetylcholinesterase activity, and subsequent determination of avian mortality were reviewed to determine those that could be used to evaluate LiquidPARAM performance. Each of the selected studies (Booth et al. 1989; Jorgensen et al. 1989) reported mortality from applications of flowable carbofuran. The exposure scenarios for the selected studies were run in LiquidPARAM to determine how close model predictions were to field observations. For the two field studies selected, LiquidPARAM predictions and field observations of mortality were similar, with LiquidPARAM slightly over-predicting risk. Conversely, EPA's TIM v1 vastly over-estimated risk of carbofuran compared to field observations (Fig. 10). Although LiquidPARAM model predictions and field study results were fairly close 
for carbofuran, our analyses described herein indicate that LiquidPARAM may be more substantially over-predicting risk of flowable CPY. The small number of incidents (2) involving CPY reported since 2002 suggests that the current labels for CPY are generally protective of birds (SI Appendix 4).

\subsection{Uncertainties of the Refined Risk Assessment for Flowable CPY}

This refined assessment of acute and chronic risks of CPY to birds contains uncertainties. Uncertainties in the problem formulation and assessment of exposure and effects can influence the characterization of risks. It is therefore important to identify the sources of uncertainty in the assessment, and specify the magnitude and direction of their influence.

The following sources of uncertainty were identified in this refined risk assessment for birds (Table 7):

- The refined risk assessment considered exposure of birds to CPY via ingestion of food and water. As discussed in Sect. 2.4, dermal contact, inhalation and preening are unlikely to be important exposure routes for birds in fields treated with flowable CPY. At present, refined models are lacking to quantify these exposure routes in birds.

- The refined risk assessment considered exposure to 15 focal species. Thus, there is a possibility that bird species not considered in this assessment are at risk on or near CPY-treated fields. The focal species were selected because of their affinity for agricultural areas and the crops considered in this assessment. This group of species is more likely to be exposed to flowable CPY than would most other bird species. Furthermore, they span a range of sizes and taxonomic groups, and are representative of bird species found in regions where CPY is used. However, it is conceivable that there are bird species at greater risk to flowable CPY than those included for the 11 crops considered in this assessment.

- When there was uncertainty, these sources were quantified and incorporated in the exposure analyses (e.g., free metabolic rate, initial dietary residue levels following application). Thus, these sources of uncertainty have been explicitly accounted for in the risk estimates described here. Other sources of uncertainty, however, could not be fully accounted for in LiquidPARAM, generally because data were too scarce to reliably parameterize distributions. For example, acute dose-response curves were unavailable for all focal species except the northern bobwhite (C. virginianus) and red-winged blackbird (A. phoeniceus). The general approach for input variables for which values were uncertain was to use conservative point estimates or rely on surrogate approaches (e.g., the species sensitivity distribution approach to estimate dose-response curves for species of differing sensitivities). The model evaluation exercise indicated that model predictions reasonably replicated patterns of mortality observed in field studies conducted 


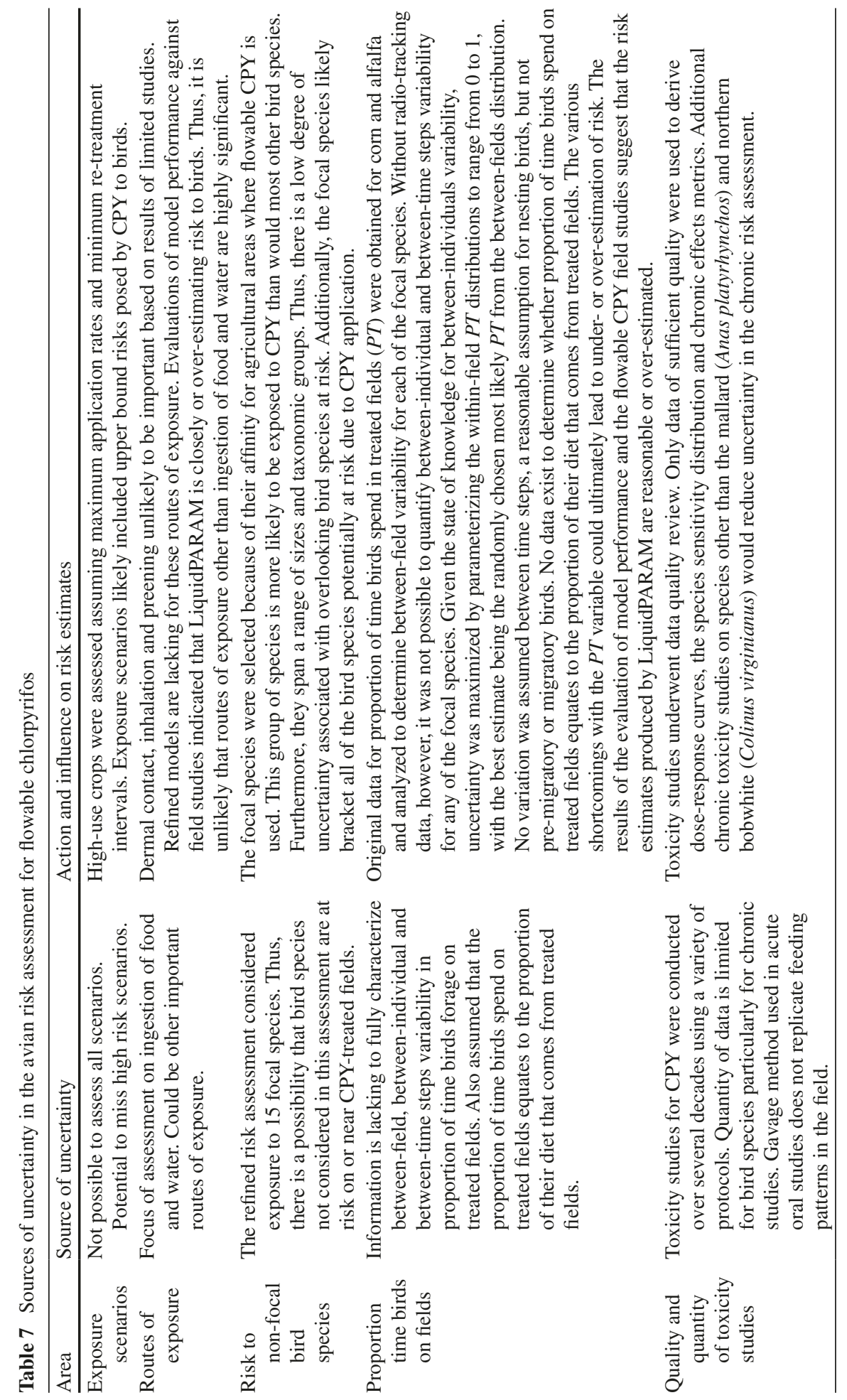


for carbofuran in corn and alfalfa. Overall, it appears that the LiquidPARAM performed well for carbofuran, but may have over-predicted risk for flowable CPY, based on the results of field studies conducted with CPY.

\section{Risk Characterization for Granular Chlorpyrifos}

For each exposure scenario, acute risk was determined using the same approach as described in Sect. 6 for flowable chlorpyrifos.

As with flowable CPY, the dose-response curve used to estimate acute risk depended on the focal species. If a dose-response curve was available for the focal species of interest, that curve was used (i.e., northern bobwhite (C. virginianus), red-winged blackbird (A. phoeniceus)). In the absence of species-specific doseresponse curves, acute dose-response curves were generated for three hypothetical species representing a range of sensitivities. In this section, the results from the GranPARAM modeling exercise are discussed. In addition, the results of avian field studies are discussed and compared to the results from the modeling exercise. The section concludes with a discussion of sources of uncertainty and strengths of the assessment for granular CPY.

\subsection{Modeled Acute Risks from Granular CPY}

Simulations conducted for granular CPY indicated that, with two exceptions, all bird species were at de minimis risk, even if they had high sensitivity to granular CPY (Table 8). The two exceptions were for horned lark in corn/sweet corn and tobacco, assuming that horned larks (E. alpestris) are highly sensitive to CPY. Horned larks forage more in row crops than do any other focal species considered in this assessment (SI Appendix 3, Sect. 1.2). In corn/sweet corn and tobacco, survival of horned larks was predicted to be $>95 \%$ (Table 8 ).

\subsection{Results of Field Studies for Granular CPY}

Avian field studies were performed with Lorsban $15 \mathrm{G}$ on corn fields in Iowa (Frey et al. 1994). Lorsban $15 \mathrm{G}$ was applied at $2.87 \mathrm{~kg} \mathrm{ha}^{-1}\left(2.6 \mathrm{lb}\right.$ ai A $\left.\mathrm{A}^{-1}\right)$ at-planting (ground banded), and at $1.07 \mathrm{~kg} \mathrm{ha}^{-1}\left(0.975 \mathrm{lb}\right.$ ai A$\left.{ }^{-1}\right)$ during the whorl and tassel stages (aerial broadcast). Monitoring of field sites for birds exhibiting signs of toxicity was done prior to each application and for 13-d following each application, including abundance determinations, carcass search efficiency evaluations, and residue analyses. 


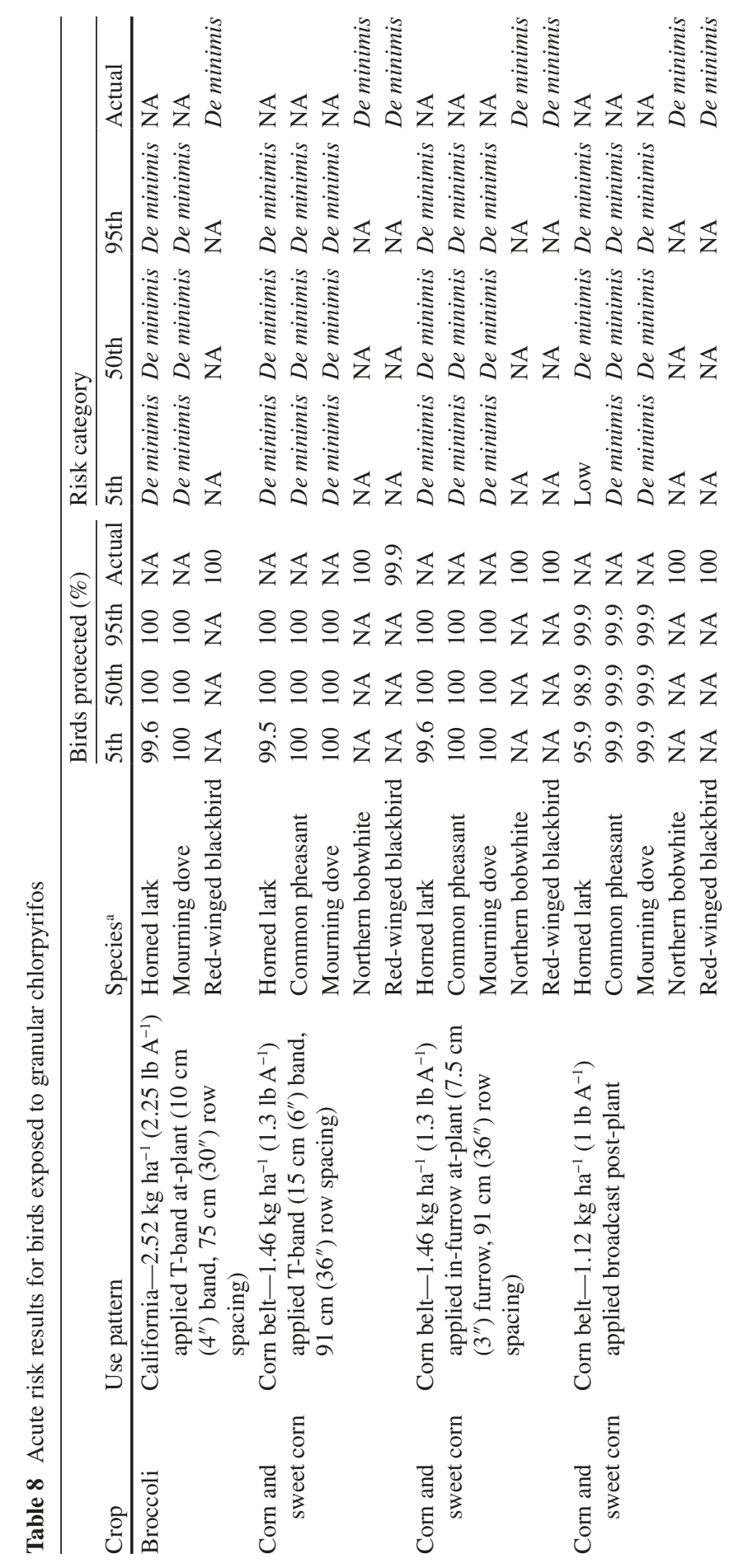




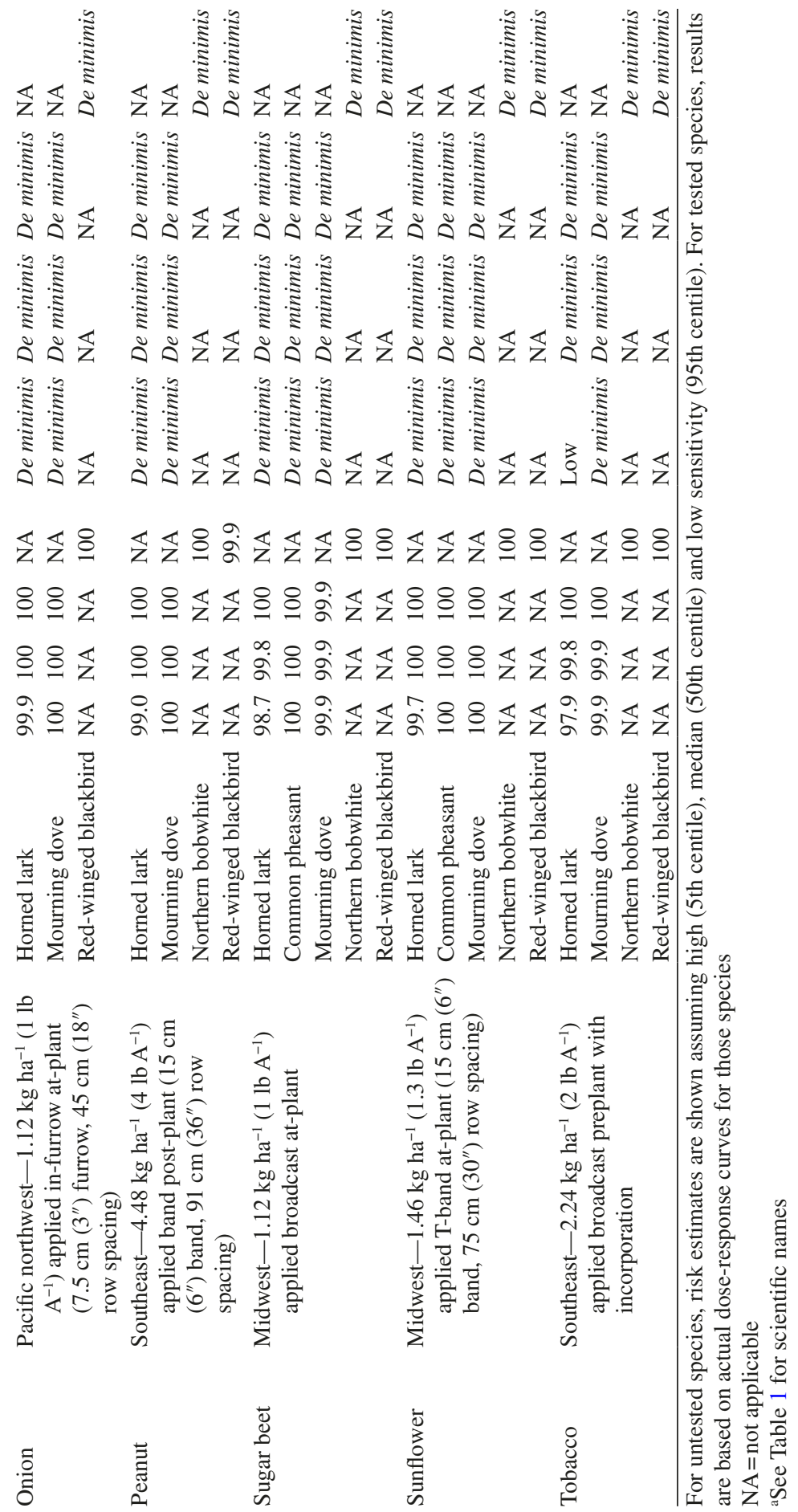


Following the at-plant and post-plant applications, there were no differences in avian mortality between treated and control fields. Remains of birds on granular treated fields were insufficient for residue analysis following application during the tassel stage.

In a similar study (Anderson et al. 1998), Lorsban 15G was applied in a T-band scenario at a rate of $1.34 \mathrm{~kg} \mathrm{ha}^{-1}\left(1.2 \mathrm{lb}^{\mathrm{ai}} \mathrm{A}^{-1}\right)$ during planting of corn crops in Iowa. Nest boxes were erected for starlings (Sturnus vulgaris) on both the experimental and control sites. Occupancy of nest boxes was not affected by application of CPY to the experimental field, nor was reproduction. Analysis of 13-d old nestlings showed that there was no difference in AChE activities among birds from nest boxes on the two sites. Wild birds were also caught on the two sites and blood samples taken to measure activity of AChE in plasma. No significant differences between the treated and control sites were detected. Concentrations of CPY measured in food items for nestlings were generally undetectable, but concentrations as great as $10.6 \mathrm{mg}$ ai $\mathrm{kg}^{-1}$ wwt were measured in a few samples.

Field studies to determine the potential effects of application of Lorsban $15 \mathrm{G}$ to corn corroborate the predictions from GranPARAM of very limited mortality of birds. Rates of application in field studies (1.09-2.91 $\left.\mathrm{kg} \mathrm{ha}^{-1}\left(0.975-2.6 \mathrm{lb}^{\mathrm{ai} \mathrm{A}} \mathrm{A}^{-1}\right)\right)$ were similar to or exceeded the maximum permitted application rates on the Lorsban $15 \mathrm{G}$ label for corn (i.e., $1.46 \mathrm{~kg} \mathrm{ha}^{-1}$ (1.3 $\mathrm{lb}$ ai $\mathrm{A}^{-1}$ ) applied T-band or in-furrow, $1.12 \mathrm{~kg} \mathrm{ha}^{-1}$ (1 $\mathrm{lb}$ ai $\left.\mathrm{A}^{-1}\right)$ applied broadcast), broccoli $\left(2.52 \mathrm{~kg} \mathrm{ha}^{-1}\left(2.25 \mathrm{lb}\right.\right.$ ai A $\left.{ }^{-1}\right)$ applied T-band), onion (1.12 $\mathrm{kg} \mathrm{ha}^{-1}$ (1 $\mathrm{lb}$ ai $\left.\mathrm{A}^{-1}\right)$ applied in-furrow), sugarbeet (1.12 $\mathrm{kg} \mathrm{ha}^{-1}$ (1 $\left.\mathrm{lb}_{\text {ai }} \mathrm{A}^{-1}\right)$ applied broadcast), sunflower $\left(1.46 \mathrm{~kg} \mathrm{ha}^{-1}\left(1.3 \mathrm{lb}\right.\right.$ ai A $\left.\mathrm{A}^{-1}\right)$ applied T-band) and tobacco $\left(2.24 \mathrm{~kg} \mathrm{ha}^{-1}\left(2 \mathrm{lb}\right.\right.$ ai $\left.\mathrm{A}^{-1}\right)$ applied broadcast with incorporation) (Table 3 ). Only peanuts have a higher maximum application rate (4.48 $\mathrm{kg} \mathrm{ha}^{-1}$ (4 $\mathrm{lb}^{\mathrm{ai}} \mathrm{A}^{-1}$ ) applied in a band) than the highest application rate used in the Frey et al. (1994) field study.

In a study conducted by Worley et al. (1994), Dursban 2.5G granular CPY was applied to plots of turf on golf courses in central Florida to monitor the effects on birds. Granular CPY was applied twice at a rate of $4.48 \mathrm{~kg} \mathrm{ha}^{-1}\left(4 \mathrm{lb}\right.$ ai A $\left.{ }^{-1}\right)$ with a 21-d interval. For 13-d following each application, the golf courses were searched for casualties. Two dead birds were found following the granular applications, which was not statistically different from total bird mortality on control sites.

\subsection{Strengths of the Refined Assessment for Granular CPY}

The refined risk assessment for granular CPY built upon the refined model originally developed by Moore et al. (2010c). The major strengths of this model include:

- Use of an exposure model that explicitly accounted for factors affecting uptake of CPY granules by birds in treated fields. These factors included: availability of natural grit in the size ranges favored by birds, application technique and rate, granule:grit preference factor, spill attraction factor, spill size and concentration, and many others. The method used by EPA (USEPA 2004b) in their screening-level avian assessments for granular pesticides (i.e., estimating $L_{50} \mathrm{~S} \mathrm{ft}^{-2}$ ) does not consider these factors in assessing exposure. 
- Derivation of species-specific dose-response curves for northern bobwhite and red-winged blackbird. This approach makes better use of the available toxicity data than does use of a benchmark based on the most sensitive response observed in birds. In the risk analyses, the dose-response curves enabled a determination of the fate of each bird (i.e., dead or alive) in the simulation. The use of the SSD approach permitted exploration of risks for untested bird species by assuming a range of sensitivities to $\mathrm{CPY}$.

\subsection{Uncertainties in the Refined Risk Assessment for Granular CPY}

The refined risk assessment of granular CPY to birds contains uncertainties. In this assessment, conservative point estimates were used when the available data were inadequate to define an input distribution (e.g., daily grit retention). Thus, the assessment erred on the side of conservatism (i.e., over-estimating risk).

The following sources of uncertainty were identified in the refined risk assessment for granular CPY (Table 9):

- The refined risk assessment considered exposure of birds to granular CPY via inadvertent ingestion of grit. Exposure to granular CPY by dermal contact, inhalation or consumption of CPY in water, insects, and plant material were not the focus of the assessment. CPY from granular formulations is not expected to occur at elevated concentrations in the atmosphere, nor is it expected to accumulate or persist in the field environment (Solomon et al. 2001). Given that granular CPY is formulated on clay particles, birds are unlikely to mistake pesticide granules for seeds.

- The refined risk assessment considered exposure to five focal species. Thus, there is a possibility that bird species not considered in this assessment are at risk on or near CPY-treated fields. The focal species were selected because of their affinity for grit and agricultural areas. This group of species is more likely to be exposed to granular CPY than would most other bird species. Furthermore, they span a range of sizes and taxonomic groups, and are representative of species of birds found in regions where granular CPY is used. Thus, there is little uncertainty associated with overlooking bird species at risk.

- GranPARAM has a number of sources of uncertainty. Where possible, these sources were quantified and incorporated in the exposure analyses (e.g., variation in availability of natural grit particles, grit counts in bird gizzards). Thus, these sources of uncertainty have been explicitly accounted for in the risk estimates described here. Other sources of uncertainty, however, could not be accounted for in GranPARAM, generally because data were too scarce. Examples include: granule:grit preference factor, daily grit retention in bird gizzards, and use of the field margin. The general approach for input variables with high uncertainty was to use conservative point estimates. The model evaluation exercise 
Table 9 Sources of uncertainty in avian risk assessment for granular chlorpyrifos

\begin{tabular}{|c|c|c|}
\hline Area & Source of uncertainty & Action and influence on risk estimates \\
\hline $\begin{array}{l}\text { Exposure } \\
\text { scenarios }\end{array}$ & $\begin{array}{l}\text { Not possible to assess all } \\
\text { scenarios. Potential to miss } \\
\text { high risk scenarios. }\end{array}$ & $\begin{array}{l}\text { Most highly-used crops were assessed at } \\
\text { maximum application rates. Exposure } \\
\text { scenarios included upper bound risk } \\
\text { posed by granular CPY to birds. }\end{array}$ \\
\hline $\begin{array}{l}\text { Routes of } \\
\quad \text { exposure }\end{array}$ & $\begin{array}{l}\text { Focus of assessment was on } \\
\text { inadvertent ingestion of } \\
\text { CPY granules for grit by } \\
\text { birds. There could be other } \\
\text { important routes of } \\
\text { exposure. }\end{array}$ & $\begin{array}{l}\text { Clay formulation and short half-life of } \\
\text { granules in treated fields suggest that } \\
\text { potential exposure routes such as } \\
\text { inhalation, dermal exposure and } \\
\text { ingestion for food are of minor } \\
\text { importance. }\end{array}$ \\
\hline $\begin{array}{l}\text { Risk to non-focal } \\
\text { bird species }\end{array}$ & $\begin{array}{l}\text { The refined risk assessment } \\
\text { considered exposure to five } \\
\text { focal species. Thus, there } \\
\text { is a possibility that bird } \\
\text { species not considered in } \\
\text { this assessment are at risk } \\
\text { on or near CPY-treated } \\
\text { fields. }\end{array}$ & $\begin{array}{l}\text { The focal species were selected because of } \\
\text { their affinity for grit and agricultural } \\
\text { areas. This group of species is more } \\
\text { likely to be exposed to granular CPY } \\
\text { than would most other bird species. } \\
\text { Furthermore, they span a range of sizes and } \\
\text { taxonomic groups, and are representative } \\
\text { of bird species found in regions where } \\
\text { granular CPY is used. Thus, there is a } \\
\text { low degree of uncertainty associated with } \\
\text { overlooking bird species at risk. }\end{array}$ \\
\hline $\begin{array}{l}\text { Proportion time } \\
\text { birds on fields }\end{array}$ & See Table 7. & See Table 7 \\
\hline $\begin{array}{l}\text { Granule:Grit } \\
\text { preference } \\
\text { factor (GGPF) }\end{array}$ & $\begin{array}{l}\text { Only one study quantified } \\
\text { GGPF for CPY. }\end{array}$ & $\begin{array}{l}G G P F \text { of } 0.078 \text { from study on controlled } \\
\text { study on house sparrows (Passer } \\
\text { domesticus). The uncertainty arising } \\
\text { from the limited available information on } \\
\text { GGPF could lead to under- or over- } \\
\text { estimation of risk. }\end{array}$ \\
\hline $\begin{array}{c}\text { Other variables in } \\
\text { GranPARAM }\end{array}$ & $\begin{array}{l}\text { Several variables (e.g., spill } \\
\text { concentration factor, size } \\
\text { of spills) were difficult to } \\
\text { parameterize because of } \\
\text { limited data. }\end{array}$ & $\begin{array}{l}\text { Sensitivity analyses involving one-at-a-time } \\
\text { manipulations of uncertain variables } \\
\text { indicated they had little influence on } \\
\text { predicted CPY exposure within } \\
\text { parameter ranges that could be reasonably } \\
\text { expected to occur in CPY-treated fields. } \\
\text { Comparison of model predictions to } \\
\text { results of field studies also indicated that } \\
\text { GranPARAM performed well, though the } \\
\text { database for this comparison was } \\
\text { limited. }\end{array}$ \\
\hline $\begin{array}{l}\text { Quality and } \\
\text { quantity of } \\
\text { toxicity studies }\end{array}$ & See Table 7. & See Table 7. \\
\hline
\end{tabular}

indicated that model predictions reasonably replicated numbers of pesticide granules ingested in by birds in field studies, although this dataset is limited. Overall, it appears that the GranPARAM performs well, despite uncertainties regarding some input variables. 


\section{Summary}

Refined risk assessments for birds exposed to flowable and granular formulations of CPY were conducted for a range of current use patterns in the United States. Overall, the collective evidence from the modeling and field study lines of evidence indicate that flowable and granular CPY do not pose significant risks to the bird communities foraging in agro-ecosystems in the United States. The available information indicates that avian incidents resulting from the legal, registered uses of CPY have been very infrequent since 2002 (see SI Appendix 3). The small number of recent incidents suggests that the current labels for CPY are generally protective of birds. However, incident data are uncertain because of the difficulties associated with finding dead birds in the field and linking any mortality observed to CPY.

Flowable CPY is registered for a variety of crops in the United States including alfalfa, brassica vegetables, citrus, corn, cotton, grape, mint, onion, peanut, pome and stone fruits, soybean, sugar beet, sunflower, sweet potato, tree nuts, and wheat under the trade name Lorsban Advanced. The major routes of exposure for birds to flowable CPY were consumption of treated dietary items and drinking water. The Liquid Pesticide Avian Risk Assessment Model (LiquidPARAM) was used to simulate avian ingestion of CPY by these routes of exposure. For acute exposure, LiquidPARAM estimated the maximum retained dose in each of 20 birds on each of 1,000 fields that were treated with CPY over the 60-d period following initial application. The model used a 1-h time step. For species lacking acceptable acute oral toxicity data (all focal species except northern bobwhite (C. virginianus) and redwinged blackbird (A. phoeniceus)), a species sensitivity distribution (SSD) approach was used to generate hypothetical dose-response curves assuming high, median and low sensitivity to CPY. For acute risk, risk curves were generated for each use pattern and exposure scenario. The risk curves show the relationship between exceedence probability and percent mortality. The results of the LiquidPARAM modeling exercise indicate that flowable CPY poses an acute risk to some bird species, particularly those species that are highly sensitive and that forage extensively in crops with high maximum application rates (e.g., grapefruit, orange). Overall, most bird species would not experience significant mortality as a result of exposure to flowable CPY. The results of a number of field studies conducted at application rates comparable to those on the Lorsban Advanced label indicate that flowable CPY rarely causes avian mortality. The results of the field studies suggest that LiquidPARAM is likely over-estimating acute risk to birds for flowable CPY.

For chronic exposure, LiquidPARAM estimated the maximum total daily intake (TDI) over a user-specified exposure duration (28-d in the case of CPY). The maximum average TDI was compared to the chronic NOEL and LOEL from the most sensitive species tested for CPY, the mallard. This comparison was done for each of the 20 birds in each of the 1000 fields simulated in LiquidPARAM. The outputs are estimates of the probabilities of exceeding the NOEL and LOEL. LiquidPARAM did not predict significant adverse effects resulting from chronic exposure to flowable CPY. The small number of incidents (2) involving CPY reported since 2002 suggests that the current labels for CPY are generally protective of birds. 
Granular CPY is registered for a wide variety of crops including brassica vegetables, corn, onion, peanut, sugar beet, sunflower, and tobacco under the trade name Lorsban $15 \mathrm{G}$. Consumption of grit is required by many birds to aid in digestion of hard dietary items such as seeds and insects. Because CPY granules are in the same size range as natural grit particles consumed by birds, there is a potential for birds to mistakenly ingest granular CPY instead of natural grit. We developed the Granular Pesticide Avian Risk Model (GranPARAM) to simulate grit ingestion behavior by birds. The model accounts for proportion of time that birds forage for grit in treated fields, relative proportions of natural grit versus pesticide granules on the surface of treated fields, rates of ingestion of grit, attractiveness of pesticide granules relative to natural grit and so on. For CPY, each model simulation included 20 birds on each of 1,000 fields to capture variability in rates of ingestion of grit and foraging behavior between birds within a focal species, and variability in soil composition between fields for the selected use pattern. The estimated dose for each bird was compared with randomly chosen doses from relevant dose-response curves for CPY. Our analysis for a wide variety of use patterns on the Lorsban 15G label found that granular CPY poses little risk of causing mortality to bird species that frequent treated fields immediately after application. The predictions of the model have been confirmed in several avian field studies conducted with Lorsban $15 \mathrm{G}$ at application rates similar to or exceeding maximum application rates on the Lorsban 15G label.

Acknowledgments The development of LiquidPARAM and this manuscript was guided by the advice of two expert panels, one for carbofuran and the other for CPY. The authors wish to thank the members of the expert panels that included Lou Best, Larry Brewer, Chris Cutler, Jeff Giddings, Don Mackay, John Purdy, and Marty Williams. The authors also thank Don Carlson of FMC Corporation, Dylan Fuge from Latham and Watkins LLP, and Nick Poletika and Mark Douglas from Dow AgroSciences for their helpful contributions to the development and preparation of this manuscript. We thank the anonymous reviewers of this paper for their suggestions and constructive criticism. Prof. Giesy was supported by the Canada Research Chair program, a Visiting Distinguished Professorship in the Department of Biology and Chemistry and State Key Laboratory in Marine Pollution, City University of Hong Kong, the 2012 "High Level Foreign Experts" (\#GDW20123200120) program, funded by the State Administration of Foreign Experts Affairs, the P.R. China to Nanjing University and the Einstein Professor Program of the Chinese Academy of Sciences. This study was funded by Dow AgroSciences.

Open Access This article is distributed under the terms of the Creative Commons Attribution Noncommercial License, which permits any noncommercial use, distribution, and reproduction in any medium, provided the original author(s) and source are credited.

\section{References}

Aldenberg T, Jaworska JS, Traas TP (2002) Normal species sensitivity distributions and probabilistic ecological risk assessment. In: Posthuma L, Suter GW, Traas T (eds) Species sensitivity distributions in ecotoxicology. CRC, Boca Raton, FL, pp 49-102

Allen TFH, Starr TB (1982) Hierarchy: perspectives for ecological complexity. The University of Chicago Press, Chicago, IL, 326 pp 
Anderson TA, Richards SM, McMurray ST, Hooper MJ (1998) Avian response to chlorpyrifos exposure in corn agroecosystems. Dow AgroSciences, Indianapolis, IN (unpublished report)

Barron MG, Woodburn KB (1995) Ecotoxicology of chlorpyrifos. Rev Environ Contam Toxicol 144:1-93

Bauriedel WR (1986) Fate of 14C-chlorpyrifos administered to laying hens. Dow Chemical, USA, Midland, MI (unpublished report)

Beavers JB, Martin KH, Gallagher SP (2007) GF-1668: a dietary LC50 study with the northern bobwhite. Dow Chemical Company, Midland, MI (unpublished report)

Bennett RS (1989) Role of dietary choices in the ability of bobwhite to discriminate between insecticide-treated and untreated food. Environ Toxicol Chem 8:731-738

Best LB (1977) Nestling biology of the field sparrow. Auk 94:308-319

Best LB, Gionfriddo JP (1994) House sparrow preferential consumption of carriers used for pesticide granules. Environ Toxicol Chem 13:919-925

Best LB, Stafford TR, Mihaich EM (1996) House sparrow preferential consumption of pesticide granules with different surface coatings. Environ Toxicol Chem 15:1763-1768

Best LB, Murray LD (2003) Estimating the proportion of diet birds take from treated agricultural fields. CropLife America, Washington, DC

Bidlack HD (1979) Degradation of chlorpyrifos in soil under aerobic, aerobic/anaerobic and anaerobic conditions. Dow Chemical, Midland, MI (unpublished report)

Booth GM, Best LB, Carter MW, Jorgensen CD (1989) Effects of Furadan 4F on birds associated with Kansas and Oklahoma alfalfa fields. FMC Corporation, Philadelphia, PA (unpublished report)

Brewer LW, Kaczor MH, Miller VC (2000a) Dursban 10.5 LEE: 14-day avian acute oral toxicity test with northern bobwhite (Colinus virginianus). Dow Chemical Company, Midland, MI (unpublished report)

Brewer LW, Kaczor MH, Miller VC (2000b) Lorsban 2.5P: 14-day avian acute oral toxicity test with northern bobwhite (Colinus virginianus). Dow Chemical Company, Midland, MI (unpublished report)

Brown KC, Stamp G, Kitson J (2007) Refinement of the risk to birds following application of chlorpyrifos to vines in Southern France. Dow Chemical Company, Indianapolis, IN (unpublished report)

Cairns MA, Maguire CC, Williams BA, Bennett JK (1991) Brain cholinesterase activity of bobwhite acutely exposed to chlorpyrifos. Environ Toxicol Chem 10:657-664

Campbell S, Hoxter KA, Jaber M (1990) 3,5,6-Trichloro-2-pyridinol: an acute oral toxicity study with the northern bobwhite. Dow Chemical Company, Midland, MI (unpublished report)

CCME (2013) Determination of hazardous concentrations with species sensitivity distributions, SSD master. Canadian Council of Ministers of the Environment, Ottawa, ON, Canada

Chapman RA, Harris CR (1980) Persistence of chlorpyrifos in a mineral and an organic soil. J Environ Sci Health B 15:39-46

Cutler GC, Purdy J, Giesy JP, Solomon KR (2014) Risk to pollinators from the use of chlorpyrifos in the United States. Rev Environ Contam Toxicol 231:219-265

de Vette HQM, Schoonmade JA (2001) A study on the route and rate of aerobic degradation of ${ }^{14} \mathrm{C}$-chlorpyrifos in four European soils. Dow AgroSciences, Indianapolis, IN (unpublished report)

Dittrich R, Staedtler T (2010) Chlorpyrifos in citrus orchards-field study on the status of bird communities and reproductive performance. Dow AgroSciences, Abingdon, UK (unpublished report)

Dow AgroSciences (2008) Lorsban 15G granular insecticide specimen label. Dow AgroSciences LLC, Indianapolis, IN

Dow AgroSciences (2009) Lorsban advanced insecticide supplemental labeling. Dow AgroSciences LLC, Indianapolis, IN

ECOFRAM (1999) ECOFRAM aquatic final draft reports. United States Environmental Protection Agency, Washington, DC. http://www.epa.gov/oppefed1/ecorisk/aquareport.pdf

EFSA (2008) Scientific opinion of the panel on plant protection products and their residues on a request from the EFSA PRAPeR Unit on risk assessment for birds and mammals. EFSA J 734:1-181 
Fautin RW (1941) Development of nestling yellow-headed blackbirds. Auk 58:215-232

Fink R (1977) Eight-week feeding study—mallard duck: chlorpyrifos. Dow Chemical, Midland MI (unpublished report)

Fink R (1978a) One-generation reproduction study—mallard duck: chlorpyrifos. Dow Chemical, Midland, MI (unpublished report)

Fink R (1978b) The effect of chlorpyrifos during a one-generation reproduction study on bobwhite. Dow Chemical, Midland, MI (unpublished report)

Frey LT, Krueger HO, Palmer DA (1994) Lorsban insecticide: an evaluation of its effects upon avian and mammalian species on and around corn fields in Iowa. DowElanco, Indianapolis, IN (unpublished report)

Gallagher SP, Palmer DA, Krueger HO (1994) Lorsban insecticide a pilot year evaluation of its effects upon avian and mammalian species on and around citrus groves in California. DowElanco, Indianapolis, IN (unpublished report)

Gallagher SP, Palmer DA, Krueger HO (1996) Chlorpyrifos technical: an acute oral toxicity study with the house sparrow. Dow Chemical, Midland, MI (unpublished report)

Gallagher SP, Beavers JB (2006) GF-1668: an acute oral toxicity study with the northern bobwhite. Dow Chemical Company, Midland, MI (unpublished report)

Gallagher SP, Beavers JB (2007) Chlorpyrifos technical: a single day dietary exposure with the northern bobwhite. Dow Chemical, Midland, MI (unpublished report)

Giddings JM, Williams WM, Solomon KR, Giesy JP (2014) Risks to aquatic organisms from the use of chlorpyrifos in the United States. Rev Environ Contam Toxicol 231:119-162

Giddings JM, Anderson TA, Hall LW Jr, Kendall RJ, Richards RP, Solomon KR, Williams WM (2005) A probabilistic aquatic ecological risk assessment of atrazine in North American surface waters. SETAC, Pensacola, FL, $432 \mathrm{pp}$

Gomez LE (2009) Use and benefits of chlorpyrifos in U.S. Agriculture. Dow AgroSciences, Indianapolis, IN (unpublished report)

Hill EF, Camardese MB (1984) Toxicity of acetylcholinesterase insecticides to birds: technical grade versus granular formulations. Ecotoxicol Environ Saf 8:551-563

HSDB (2013) Hazardous substances data bank. Chlorpyrifos. National Library of Medicine. http:// toxnet.nlm.nih.gov/cgi-bin/sis/search/f?./temp/ ntQQXy:1. Accessed February 2013

Hubbard PM, Beavers JB (2008) GF-2153: an acute oral toxicity study with the northern bobwhite. Dow Chemical Company, Midland, MI (unpublished report)

Hubbard PM, Beavers JB (2009) Chlorpyrifos: an acute oral toxicity study with the northern bobwhite using two excipients. Dow Chemical Company, Midland, MI (unpublished report)

Hudson RH, Tucker RK, Haegele MA (1984) Handbook of toxicity of pesticides to wildlife, 2nd edn. United States Department of the Interior Fish and Wildlife Service, Washington, DC

Jorgensen CD, Whitmore RC, Booth GM, Carter MW, Smith HD (1989) Effects of Furadan ${ }^{\circledR}$ 4F on birds associated with Nebraska and Texas/New Mexico corn fields. FMC Corporation, Philadelphia, PA (unpublished report)

Kaczor MH, Miller VC (2000) Lorsban 50W: 14-day avian acute oral toxicity test with northern bobwhite (Colinus virginianus). Dow Chemical Company, Midland, MI (unpublished report)

Kenaga EE, Fink RJ, Beavers JB (1978) Dietary toxicity tests with mallards simulating residue decline of chlorpyrifos and avoidance of treated food. Dow Chemical Company, Midland, MI (unpublished report)

Kessel B (1957) A study of the breeding biology of the European starling (Sturnus vulgaris L.) in North America. Am Midl Nat 58:257-331

Kluijver HN (1950) Daily routines of the great tit, Parus m major L 38:99-135

Kunz SE, Radeleff RD (1972) Evaluation of the hazard of chlorpyrifos soil treatments on turkeys. J Econ Entomol 65:1208-1209

Lehman-McKeeman LD (2008) Adsoption, distribution, and excretion of toxicants. In: Klaasen CD (ed) Casaret and Doull's toxicology: the basic science of poisons. McGraw-Hill, New York, NY, pp 131-159

Long RD, Hoxter KA, Jaber M (1990) 3,5,6-Trichloro-2-pyridinol: a dietary LC50 study with the mallard. Dow Chemical Company, Midland, MI (unpublished report) 
Long RD, Smith GJ, Beavers JB (1991) XRM 5160 (microencapsulated insecticide): a dietary LC50 study with the mallard. Dow Chemical Company, Midland, MI (unpublished report)

Luttik R, de Snoo GR (2004) Characterization of grit in arable birds to improve pesticide risk assessment. Ecotoxicol Environ Saf 57:319-329

Mackay D, Giesy JP, Solomon KR (2014) Fate in the environment and long-range atmospheric transport of the organophosphorus insecticide, chlorpyrifos and its oxon. Rev Environ Contam Toxicol 231:35-76

McCollister SB, Kociba RJ, Humiston CG, McCollister DD, Gehring PJ (1974) Studies of the acute and long-term oral toxicity of chlorpyrifos (O, O-diethyl-O-(3,5,6-trichloro-2-pyridyl) phosphorothionate). Food Cosmet Toxicol 12:45-61

McGregor WS, Swart RW (1968) Toxicity studies on turkeys confined on soil treated with Dursban. Dow Chemical Company, Lake Jackson, TX (unpublished report)

McGregor WS, Swart RW (1969) Toxicity studies on turkeys with Dursban insecticide (Wettable Powder Formulation TF-137) applied as a spray to range pens. Dow Chemical Company, Lake Jackson, TX (unpublished report)

Mineau P (2002) Estimating the probability of bird mortality from pesticide sprays on the basis of the field study record. Environ Toxicol Chem 21:1497-1506

Miyazaki S, Hodgson GC (1972) Chronic toxicity of Dursban and its metabolite, 3,5,6-trichloro2-pyridinol in chickens. Toxicol Appl Pharmacol 23:391-398

Moore DRJ (1998) The ecological component of ecological risk assessment: lessons from a field experiment. Human Ecol Risk Assess 4:1103-1123

Moore DRJ, Thompson RP, Rodney SI, Fischer DL, Ramanaryanan T, Hall T (2010a) Refined aquatic risk assessment for aldicarb in the United States. Integr Environ Assess Manag 6:102-118

Moore DRJ, Teed RS, Rodney SI, Thompson RP, Fischer DL (2010b) Refined avian risk assessment for aldicarb in the United States. Integr Environ Assess Manag 6:83-101

Moore DRJ, Fischer DL, Teed RS, Rodney SI (2010c) Probabilistic risk-assessment model for birds exposed to granular pesticides. Integr Environ Assess Manag 6:260-272

Moosmayer P, Wilkens S (2008) Chlorpyrifos (Dursban 480 EC) in brassica crops-field study on exposure and effects on wild birds. Dow AgroSciences, Indianapolis, IN (unpublished report)

Nagy KA (1987) Field metabolic rate and food requirement scaling in mammals and birds. Ecol Monogr 57:11-128

Nagy KA, Girard IA, Brown TK (1999) Energetics of free-ranging mammals, reptiles, and birds. Annu Rev Nutr 19:247-277

Parsons KC, Matz AC, Hooper MJ, Pokras MA (2000) Monitoring wading bird exposure to agricultural chemicals using serum cholinesterase activity. Environ Toxicol Chem 19:1317-1323

Pinkowski BC (1978) Feeding of nestling and fledgling eastern bluebirds. Wilson Bull 90:84-98

PMRA (2007) Probabilistic environmental risk assessment for terrestrial biota exposed to CPY, vol III. Pest Management Regulatory Agency, Environmental Assessment Division, Ottawa, ON

Price MA, Kunz SE, Everett RF (1972) Further evaluation of insecticides to control the chigger Neoschongastia americana on turkeys. J Econ Entomol 65:454-455

Racke KD (1993) Environmental fate of chlorpyrifos. Rev Environ Contam Toxicol 131:1-151

Reeves G (2008) Modelling the laboratory soil degradation kinetics of CPY and two metabolites (TCP and TMP) using FOCUS methodology. Dow Agrosciences, Abingdon, UK (unpublished report)

SAP (2000) Implementation plan for probabilistic ecological assessment: a consultation. FIFRA Scientific Advisory Panel Meeting, 5-7 April 2000. United States Environmental Protection Agency, FIFRA Scientific Advisory Panel, Arlington, VA. No. 2000-02

SAP (2001) Probabilistic Models and Methodologies: Advancing the ecological risk assessment process in the EPA Office of pesticide programs. FIFRA Scientific Advisory Panel Meeting, 13-16 March 2001. United States Environmental Protection Agency, FIFRA Scientific Advisory Panel, Arlington, VA. No. 2001-06 
SAP (2004) Refined (level II) Terrestrial and aquatic models—probabilistic ecological assessments for pesticides: terrestrial. FIFRA Scientific Advisory Panel Meeting, 30-31 March 2004. United States Environmental Protection Agency, FIFRA Scientific Advisory Panel, Arlington, VA. No. 2004-03

Schafer EW, Brunton RB (1971) Chemicals as bird repellents: two promising agents. J Wildl Manag 35:569-572

Schafer EW, Brunton RB (1979) Indicator bird species for toxicity determinations: is the technique usable in test method development. In: Beck JR (ed) Vertebrate pest control and management materials, vol ASTM STP 680. American Society for Testing and Materials, West Conshohocken, PA, pp 157-168

Selbach A, Wilkens S (2008a) Chlorpyrifos (Dursban 75 WG) in citrus orchards-field study on exposure and effects on wild birds. Dow AgroSciences, Indianapolis, IN (unpublished report)

Selbach A, Wilkens S (2008b) Chlorpyrifos (Dursban 75 WG) in citrus orchards-field study on exposure and effects on wild birds. Dow AgroSciences, Abingdon, UK (unpublished report)

Smith GN, Watson BS, Fischer FS (1967) The metabolism of ${ }^{36} \mathrm{Cl}$ O, O-diethyl O-(3,5,6-trichloro2-pyridyl) phosphorothioate in rats. J Agric Food Chem 15:132-138

Solomon KR, Giesy JP, Kendall RJ, Best LB, Coats JR, Dixon KR, Hooper MJ, Kenaga EE, McMurry ST (2001) Chlorpyrifos: ecotoxicological risk assessment for birds and mammals in corn agroecosystems. Human Ecol Risk Assess 7:497-632

Solomon KR, Williams M, Mackay D, Purdy J, Giddings JM, Giesy JP (2014) Properties and uses of chlorpyrifos in the United States. Rev Environ Contam Toxicol 231:13-34

Stafford JM (2007a) Assessment of the differential toxicity of carbofuran to northern mallard ducks when dosed as a single aqueous bolus versus the same dose mixed with feed. FMC Corporation, Philadelphia, PA (unpublished report)

Stafford JM (2007b) Assessment of the differential toxicity of carbofuran to northern bobwhite Quail when dosed as a single aqueous bolus versus the same dose mixed with feed. FMC Corporatio, Philadelphia, PA (unpublished report)

Stafford JM (2010) Evaluation of northern bobwhite (Colinus virginianus) food consumption relative to the concentration of chlorpyrifos in the diet. Dow AgroSciences, Indianapolis, IN (unpublished report)

Stafford TR, Best LB, Fischer DL (1996) Effects of different formulations of granular pesticides on birds. Environ Toxicol Chem 15:1606-1611

Stafford TR, Best LB (1997) Effects of granular pesticide formulations and soil moisture on avian exposure. Environ Toxicol Chem 16:1687-1693

Suter GW II, Efroymson RA, Sample BE, Jones DS (2000) Ecological risk assessment for contaminated sites. Lewis Publishers, Boca Raton, FL, 460 pp

Testai E, Buratti FM, Consiglio ED (2010) Chlorpyrifos. In: Krieger RI, Doull J, van Hemmen JJ, Hodgson E, Maibach HI, Ritter L, Ross J, Slikker W (eds) Handbook of pesticide toxicology, vol 2. Elsevier, Burlington, MA, pp 1505-1526

Timchalk C (2010) Organophosphorus insecticide pharmacokinetics. In: Krieger RI, Doull J, van Hemmen JJ, Hodgson E, Maibach HI, Ritter L, Ross J, Slikker W (eds) Handbook of pesticide toxicology, vol 2. Elsevier, Burlington, MA, pp 1409-1433

USEPA (1999) Reregistration eligibility science chapter for chlorpyrifos: fate and environmental risk assessment chapter. United States Environmental Protection Agency, Washington, DC.

USEPA (2002) Calcasieu estuary remedial investigation/feasibility study (RI/FS): baseline ecological risk assessment (BERA). United States Environmental Protection Agency, Region 6, Dallas, TX, USA. http://mapping2.orr.noaa.gov/portal/calcasieu/calc_html/pdfs/reports/berassessws.pdf

USEPA (2004a) Ecological risk assessment for General Electric (GE)/Housatonic River Site, Rest of River. United States Environmental Protection Agency, New England Region, Boston, MA.http://www.epa.gov/region1/ge/thesite/restofriver/reports/era_nov04/215498_ERA_FNL_ TOC_MasterCD.pdf

USEPA (2004b) Overview of the ecological risk assessment process in the office of pesticide programs: endangered and threatened species effects determinations. United States Environmental 
Protection Agency. Office of Prevention, Pesticides, and Toxic Substances, Office of Pesticide Programs, Washington, DC

USEPA (2005) Reregistration eligibility science chapter for carbofuran. environmental fate and effects chapter. environmental risk assessment and human drinking water exposure assessment. United States Environmental Protection Program, Office of Pesticide Programs, Washington, DC

USEPA (2008) Terrestrial investigation model version 2.1. United States Environmental Protection Agency, Office of Pesticide Programs, Washington, DC.

USEPA (2008b) Problem formulation for the environmental fate and ecological risk, endangered species and drinking water assessments in support of the registration review of chlorpyrifos. United States Environmental Protection Agency, Office of Pesticide Programs, Washington, DC

USEPA (2009) Chlorpyrifos final work plan. Registration review. United States Environmental Protection Agency, Office of Pesticide Programs, Washington, DC

USEPA (2010) Screening tool for inhalation risk (STIR) version 1.0 Washington, DC. United States Environmental Protection Agency, Office of Pesticide Programs, Washington, DC.

USEPA (2011) Revised chlorpyrifos preliminary registration review drinking water assessment. United States Environmental Protection Agency, Office of Chemical Safety and Pollution Prevention, Washington, DC, USA. PC Code 059101 http://www.epa.gov/oppsrrd1/registration review/chlorpyrifos/EPA-HQ-OPP-2008-0850-DRAFT-0025\%5B1\%5D.pdf

Wildlife International (1978) Eleven-day toxicant 2 x LC50 option with untreated food-mallard duck. Dow Chemical Company, Midland, MI (unpublished report)

Wilkens S, Frese I, Schneider K (2008) Chlorpyrifos (Dursban 480 EC): residues of chlorpyrifos in invertebrates after spray application of Dursban $75 \mathrm{WP}$ in citrus orchards-magnitude and time course of residue decline. Dow AgroSciences, Abingdon, UK (unpublished report)

Williams WM, Giddings JM, Purdy J, Solomon KR, Giesy JP (2014) Exposures of aquatic organisms resulting from the use of chlorpyrifos in the United States. Rev Environ Contam Toxicol 231:77-118

Wolf C, Riffel M, Weyman G, Douglas M, Norman S (2010) Telemetry-based field studies for assessment of acute and short-term risk to birds from spray applications of chlorpyrifos. Environ Toxicol Chem 29:1795-1803

Worley KB, Frey LT, Palmer DA, Krueger HO (1994) Dursban insecticide: an evaluation of its effects upon avian and mammalian species on and around golf courses in fall in Florida. Dow Chemical Company, Midland, MI (unpublished report) 